\title{
The Role of Digital Media in Shaping Youth Planetary Health Interests in the Global Economy
}

\author{
Ibrahim Niankara ${ }^{1, *(\mathbb{D}}$, Muhammad Noor Al adwan ${ }^{2}$ and Aminata Niankara ${ }^{3}$ \\ 1 College of Business, Al Ain University, Abu Dhabi P.O. Box 112612, UAE \\ 2 College of Communication \& Media, Al Ain University, Abu Dhabi P.O. Box 112612, UAE; \\ muhammadnoor.aladwan@aau.ac.ae \\ 3 Department of Cardiology, The National Office of Workers' Health (Office de Santé des Travailleurs-OST), \\ Ouagadougou P.O. Box 7036, Burkina Faso; niankaraaminata@yahoo.fr \\ * Correspondence: ibrahim.niankara@aau.ac.ae; Tel.: +971-2444-4696 (ext. 539)
}

Received: 28 May 2020; Accepted: 15 July 2020; Published: 17 July 2020

check for updates

\begin{abstract}
Despite revolutionizing the work of practicing economists by providing a direct link between neo-classical economic theory and revealed market preference data, Random Utility Theory has yet to guide research applications in global market sustainability. With the worldwide adverse socio-economic effects of the 2019 coronavirus disease (COVID-19), such application now becomes timely. Therefore, relying on a Random Utility theoretic formulation of youths' preferences for the biosphere (ecosystem services, sustainability) and science-based disease prevention to characterize their planetary health interests, this paper adopts a micro-based planetary view of markets to retrospectively analyze the health and ecological implications of digital media consumption among youths in the global economy. Empirically, we rely on a mixed bivariate ordered probit specification, which is estimated using Markov Chain Monte Carlo methods. Our findings reveal a strong, positive correlation coefficient $(0.835)$ between youths' interests in the biosphere and science-based disease prevention. Moreover, digital media consumption in the form of increased frequency of ecological website visits, news blogs visits, and web-browsing on broad science, significantly reduce youths' interests in the biosphere. A similar reduction in youths' interest in science-based disease prevention is observed, from news blogs visits and web-browsing on broad science. Conversely, ecological website visits appear to raise youths' interests in science-based disease prevention. Furthermore, we find a gender-based gradient in youths' planetary health interest, in favor of the female gender. Overall, our findings confirm the appropriateness of a holistic view of health, and suggests a couple of policy implications for the long-term sustainability of our planet.
\end{abstract}

Keywords: adolescents health; bayesian methods; COVID-19; digital media; ecosystem services; planetary health; sustainable development

JEL Classification: C11; D83; I15; I18; P5; Q01

\section{Introduction}

One of the greatest contribution of science to humanity has been its progressive unveiling of the influence on human health of the environment (in all its aspects: physical, social, economic, political, cultural, and historical), and the many adverse (local and planetary) impacts that human activities have on the environment [1]. Nonetheless, throughout a good part of the modern public health era, the concept of health was circumscribed to individuals, communities, populations, and on occasion, to nations [2]. This view has led to the pursuit of health as though disconnected from our lifestyles and environments [3], as we failed to consider whether health gains were recorded at 
the expense of eroding the earth's underpinning natural systems, which provide the essential life sustaining ecosystem services such as water, food, fuel and shelter, on which the human civilization depends. Thus, contributing to past inadequate societal and public health responses to global health challenges [4].

Learning from the past, an ecological public health model was proposed to help guide policy responses [5], which integrates the material, biological, and socio-cultural aspects of public health, while accepting the complexity and non-linearity of natural systems dynamics. Emerging from this framework is planetary health $(\mathrm{PH})$, which is defined as "the health of human civilization and the state of the natural systems on which it depends" [6]. PH seeks to address the challenges of how best to protect and promote human health in an era of global earth's systems disruptions from human activities $[7,8]$. It also identifies at least six dimensions of fundamental biophysical shifts including (1) global climate system disruption; (2) resource (e.g., arable land and fresh water) scarcity; (3) bio-geochemical cycles (e.g., that of nitrogen, carbon, and phosphorus) reconfiguration; (4) widespread (water, soils and air) pollution; (5) pervasive changes in land cover and use; and (6) rapid biodiversity loss [9]. These rapid changes in the function of socio-ecological systems, with their adverse influences on ecosystem services, are reported to alter human exposures to infectious diseases [10] and natural hazards (e.g., heat waves, tropical storms, fires, droughts, and floods) [3]; and therefore affect important dimensions of human well-being.

Though more consensus remains to be achieved, agricultural expansion, bushmeat hunting, and overall human encroachment into wildlife habitat are reported to be at the roots of zoonotic diseases such as the Ebola [1] and the coronavirus disease 2019 (COVID-19) [11]. Still ongoing, the COVID-19 pandemic has plunged the world into an extraordinary crisis [12], spreading to more than 125 countries [13], with catastrophic socio-economic consequences [14,15], and demonstrating the inter-dependence of national health systems, food systems and supply chains. Attesting to this global cross-country inter-dependence, is the recent call "by the Lancet" for research papers integrating planetary health perspective that cuts across traditional domains of knowledge, governance, and economic sectors to properly address the challenges posed by COVID-19 [16].

With disregard to any national or physical borders, financial crisis, biodiversity loss, and climate change are also ongoing global challenges that require concerted efforts for their management through collective action [14]. Among other things, the mitigating responses to the Covid-19 pandemic have demonstrated that overnight transformational changes are possible [15]. In the same spirit, the pandemic provides nations with the opportunity to now come up with solutions that accelerate the global transition to nature-rich societies, with low-carbon and resilient economies.

Also representing a key milestone in the global health and development community is 2015, which marked the end of the Millennium Development Goals (MDGs) era and the launching of the 17 Sustainable Development Goals (SDGs). The SDGs define 169 targets and 230 indicators leading up to 2030 [17]. They are categorized into five groups, the so-called 5Ps: People, Planet, Partnership, Peace, and Prosperity, which countries are recommended to promote to create a sustainable world [18]. By fundamentally shifting the global health and development paradigm, the COVID-19 pandemic leaves much to be done to meet the defined health and non-health related SDGs targets by 2030 [19]. Nonetheless, and in line with the efforts undertaken globally by the United Nations (UN) country members, including the UN Convention on Biological Diversity (UNCBD), its Framework Convention on Climate Change (UNFCCC), and its General Assembly Nature Summit, the pandemic leaves nations worldwide to come up with transformative economic recovery plans that invest in people, nature, and low-carbon developments [20].

As the global consensus framework for committing efforts in the present to leave a healthy and sustainable planet for future generations, the SDGs also have at heart the well-being of children and adolescents [21]. In this regards, the Lancet commission on planetary health suggests that "Despite present limitations, the SDGs provide a great opportunity to integrate health and sustainability through the judicious selection of indicators relevant to human well-being, the enabling infrastructure for development, 
and the supporting natural systems... the landscape, ecosystems, and the biodiversity they contain can be managed to protect natural systems, and indirectly, reduce human disease risk..." [3] Moreover, "Progress toward planetary health implies the development of an improved understanding of the connections between natural systems and health,... and requires recognition of the benefits to health arising from the conservation and rehabilitation of natural systems and the mitigation of greenhouse gases and other damaging emissions that result from human activities" [1].

Furthermore, based on the notion of inter-generational justice and fairness, a life course approach to well-being, and of course sustainable economic development [22], in 2018 a Lancet commission on children's health and well-being was formed with the aim of considering ways in which society as a whole, including medical professionals and governments, can accelerate progress on the strategies adopted within the context of the SDGs to improve child health and well-being [22]. One of the concluding calls made by the commission was the urgent need to address the environmental and existential threats (such as the COVID-19 pandemic [23]) that jeopardize the future for children and adolescents. In line with youths' well-being are their interests, which focus on enjoying safe and healthy environments with family togetherness [1].

It is, therefore, within this context of emerging thoughts and scholarly actions that we undertake the present analysis to investigate the role that digital media play in shaping planetary health interests in the global youth population. Our study contributes to the scientific literature in two ways: (i) methodologically, by introducing a random utility-based bivariate ordered probit (RUMBOP) model, which innovates on the previously used models to investigate sustainability; and (ii) practically, by providing new insights of practical relevance to evidence-based sustainable policy making, not just at national or global level, but at the planetary level. Hence, we organize the rest of this paper as follows: In Section 2 we briefly review the empirical literature underpinning our research hypotheses, and the theoretical literature guiding our conceptual framework; in Section 3 we describe the methodology followed to meet our research objectives, by first presenting the data, followed by the econometric model with its identification strategy; in Section 4 we present the findings, which are discussed in Section 5; in Section 6 we conclude the analysis by first elaborating on its implications, followed by discussions of its limits and avenues for future research.

\section{Literature Review}

\subsection{Theoretical Review and Conceptual Framework}

Sustainability is a planetary property with two central components that are ecological sustainability, and economic sustainability [24]. The former is defined as "the capacity of ecosystems to remain diverse, resilient and productive over time, and to maintain the flow of ecosystem services essential for humans and other species". The latter on the other hand refers to "the capacity of economic systems, at any scale from individual households to the global economy, to remain diverse, resilient and productive over time" $[25,26]$. Ecosystems, with their human components are continually evolving complex and adaptive systems [27]. The idea of sustainable development springs from this evolving nature as "development that meets the contemporaneous needs of society without compromising the ability of future generations to meet their owns" [28]. Due to growing computing power in the last two decades, and the evolution of new mathematical modeling techniques, system modeling of socio-environmental and economic interactions and feedback, has been evolving rapidly.

The scientific literature now features numerous mathematical models with ecosystem components, which are used to study sustainable development [29]. These models typically yield qualitative and quantitative conclusions that assist policy making, and the evaluation of technologies and ecosystem management strategies. Because studies of sustainable development reach across multiple disciplines, they require an equally inter-disciplinary approach for their theoretical underpinnings [8,28]. For example, [30] discusses several mathematical models for freshwater ecosystem modeling. Within the context of open innovation research, [31] reports on the value of the quadruple-helix 
model of innovation for sustainability. In the information theory literature [32], suggests using Fisher Information (FI) as a state of order of a dynamic system, to construct the basic theory of sustainability for ecological applications. Other models relying on optimal control theory to regulate socio-ecological systems to achieve sustainability have also been proposed in the literature [33]. The challenge in this latter type of models is to mathematically formulate an objective function promoting the preservation of all aspects of human society, and its surrounding natural environment. Our adopted strategy in the current analysis departs, but complements this strand of theoretical underpinnings, with the underlying goal of maximizing youths' planetary health interests, by regulating their consumption of digitally mediated strategic health and ecological information.

To this end, we rely instead on the theory of Random Utility maximization [34-37] from the field of economics. Originally conceived in 1960 entirely in terms of ordinal utility by [38], and further extended in 1963 by [39], using an analogy of the 1859 psychological model of judgment and choice [40], along with the 1927 and 1959 versions of the derivatives models [41,42] respectively, the Random Utility Model (RUM) is a probabilistic representation of the neo-classical economic theory of individual choice.

In its original conception, the probability was derived from individual's preferences variability in the face of repeated choices from the same finite set. Seeking to make RUM more pragmatic [43], shifted this interpretation by proposing the alternative view of the probabilities as reflecting the choices of a population of individuals, where each one has only one choice. This latter interpretation has contributed to popularizing the use of RUMs among practicing economists, because of its natural alignment with markets data, and potential to inform policy making.

Since "planetary health" is defined as "the health of human civilization and the state of the natural systems on which it depends" [7], it can be dissected into two distinct but inter-related dimensions. The first of which is "the health (or state) of the biosphere" and the second dimension is "the health (or state) of the human civilization". Therefore in formulating our Random Utility Model of youth's planetary health interests, we follow McFadden's utility interpretation, and assume that the joint utility youths derive from the biosphere and good health is an indirect differentiable bivariate continuous functional of their socio-economic and demographic characteristics; along with their consumption frequency of strategically designed, digitally diffused, health and ecological information. In so doing, we use a system of two equations in the form of a bivariate linear mixed model, to jointly represent the two dimensions of planetary health, while controlling for the effects of digital media consumption, and that of the socio-economic and demographic factors described in the conceptual framework in Figure 1.

The resulting Random Utility-based conceptual framework assumes that youth derive utility from both the biosphere (ecosystem services and sustainability), and from science-based disease prevention (good health); such that youths' revealed planetary health interests are driven by their latent preferences for ecosystem services, sustainability and good health from preventive science. Our main contention in this analysis is that youths' latent preferences are shaped by their frequency of digital media consumption, as expressed in the links to be tested in Figure 1. The greater the utilities that a youth derive from the biosphere and science-based disease prevention, the greater her interests in both the biosphere and science-based disease prevention, and thus her planetary health interest. Mathematically, this is equivalent to the expressions in Equation (1), which we describe in Section 3.2.

\subsection{Empirical Review and Hypotheses Formulation}

Globally, young people age $10-24$ represent about $27 \%$ of the world population, and are more vulnerable and at greater risk of disease and poor health [44]. A recent Global Burden of Disease (GBD) report [45] suggests that changing patterns of global youth health could potentially undermine future population health and economic development globally, unless ongoing tendencies are reverted through the implementation of timely and effective strategies. In 2016, the then UN secretary general in reference to the importance of properly attending to adolescents' well-being for the sustainability of global socio-economic development, stated that: "Adolescence is a critical life stage during which individuals must have the opportunity to develop the capabilities required for realizing their full potential and 
achieving a prosperous, healthy, and fulfilling life. Transitions from adolescence to adulthood require investments in health information and services tailored to adolescents' needs, quality education, vocational training, and the chance to enter the productive workforce, as well as human rights protections and opportunities to participate in decision-making. Such investments will benefit not only young people who need them, but also their communities and countries" [46].

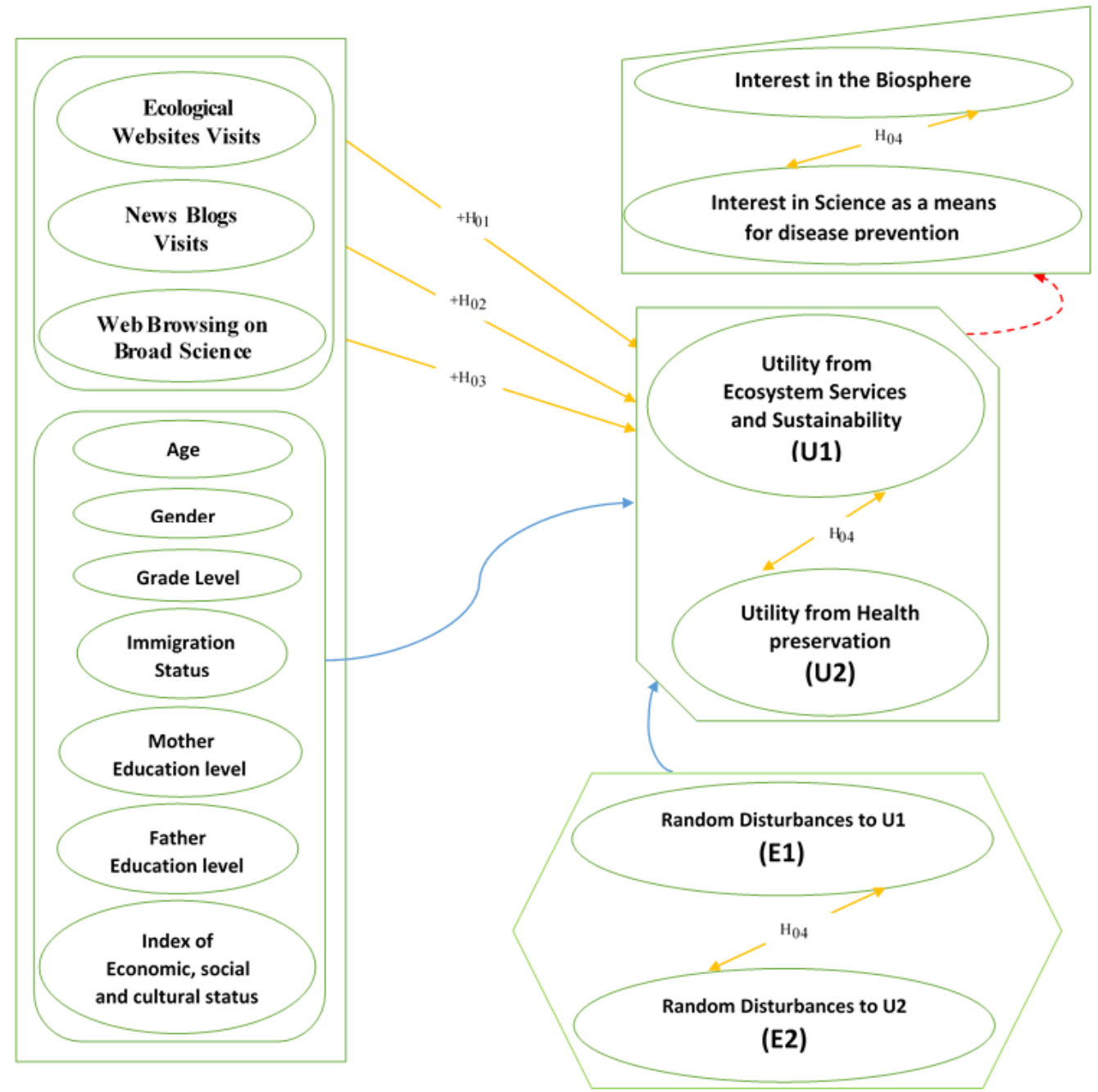

Figure 1. Random Utility-Based Conceptual Framework of Youths' Planetary Health Interest. Note that the orange links are the tested relationships in the present analysis; The blue links are structural relationships; while the dotted red link is a measurement relationship linking latent utilities to revealed interests in health and the biosphere.

Because of complex non-linear and feedback links between environmental changes and health outcomes [6], current understanding of the role of suitable climatic conditions and preserved ecosystems, in disease transmission regulation and human life and well-being support, is still imperfect [47]. Nonetheless, much of the progress recorded by humanity thus far, has been supported by the earth's ecological and biophysical systems [27]. The earth's oceans, atmosphere, and key ecosystems including wetlands, forests and tundra have contributed to regulating the world's water cycle, giving humanity freshwater for drinking and sanitation, maintaining a constant climate, providing clean air, and recycling nutrients such as nitrogen and phosphorus [20]. How the growing use of digital technology in the global youth population mediates these complex dynamics between environmental changes and health outcomes by shaping youths' planetary health interests and behaviors remains to be researched. 
Nevertheless, strategic environmental communication (SEC) theory provides the ideal set up for gathering additional evidence on this latter effect [48]. Since youths are constant users of digital technologies [49] including the Internet and mobile phones [50,51], they open up to various innovative health education and disease prevention strategies involving these technologies [52-57]. Indeed, by affecting youths' ability to readily access, understand and use unbiased evidence-based health and environmental information, digital media contributes to raising health and environmental awareness [58] and literacy [59,60], thereby reducing exposures to risk factors, and in so doing illness [61], and overall disease burden [62,63]. Importantly however, the literature on digital media influence on youth's well-being remains divided [64-67]. Although some authors report digital technology use among youths to have positive effects on their well-being [68-72]; Others report adverse effects on youth psychological well-being [73-78] and physical well-being [79,80].

Digitally mediated innovative methods for understanding youths' perceptions of their environments include community mapping [81,82], crowdsourcing through social media [83], and photovoice [84]. Digital media contributes to shaping college students' cultural attitudes including cultural awareness, receptivity, and future orientation [85]. Recent climate movement initiatives led by adolescents such as Greta Thunberg's, which mobilized in March 2019 an estimated 1.5 million students in cities worldwide, also show the potential catalytic effect of digital technologies in the form of social media platforms to harness young people's engagement into environmental and economic policy [86]. Social media platforms such as U-Report, have also proven useful for engaging youth in consultative socio-economic and environmental policy formulations [87]. For example, before the Global Conference on Primary Health Care, held on 25-26 October 2018 in Astana, Kazakhstan, the UNICEF gathered feedback from over 385,000 youth respondents using the U-Report platform to guide the discussions in the one day preparatory workshop that saw the attendance of over 100 youth participants [88].

Despite the above reported health and environmental benefits of digital technology, studies reporting on digitally mediated strategic health and environmental communication to improve the effectiveness and efficacy of health and environmental campaigns promoting planetary health interest in the global youth population remains to be undertaken. Our current investigation therefore makes use of the unique data set [89], to bridge this gap. The general question we seek to address in our current context of the COVID-19 pandemic is: How much does digital media consumption among adolescents worldwide affect their knowledge of, and interest in ecosystem services, sustainability and science-based diseases prevention?

Since "planetary health" is defined as "the health of human civilization and the state of the natural systems on which it depends" [6], we operationalize "planetary health interest" using both "interest in the biosphere (ecosystem services and sustainability)", and "interest in science as a means for disease prevention". Doing so allows us to rewrite the above research question equivalently as: How much does digital media consumption among adolescents worldwide affect their planetary health interests?

To the best of our knowledge, this research question remains to be specifically addressed in the scientific discourse. Fortunately, the Elaboration Likelihood Model (ELM) [90] from the field of information theory suggests that the framing and delivery of a message necessarily affect how it is processed, comprehended, and used in subsequent decision-making [91,92]. Various psychological barriers to health and ecological conservations have the potential to limit youths' planetary health interests and behaviors [93]. However, frames as structural manifestations of socio-ecological issues [94], could be essential psychological tools for health preservation [95] and ecological conservations [96] initiatives. Indeed, studies in persuasion research show that the cognitive challenges that environmental persuasion initiatives face, could be bypassed using strategic communication [48,97]. Therefore, strategically designed health and ecological information, which are then digitally diffused to youths, could help reduce the cognitive overload attached to complex human-ecological systems dynamics, and thereby improve youths' planetary health interests and behaviors. Hence, the rest of our research endeavor is guided by the following four hypotheses: 
Hypothesis 1 (H1). Frequent visits of ecological websites positively influence adolescents' interests in the biosphere and science-based disease prevention;

Hypothesis 2 (H2). Frequent visits of news blogs positively influence adolescents' interests in the biosphere and science-based disease prevention;

Hypothesis 3 (H3). Frequent web-browsing on broad science positively influence adolescents' interests in the biosphere and science-based disease prevention;

Hypothesis 4 (H4). A significant relationship exists between adolescents' interest in the biosphere and their interest in science-based disease prevention;

In the theory of hypothesis test, the null hypothesis always translates the state of nature on the phenomenon under investigation, and is rejected if and only if there is convincing evidence from the studied sample that it is false. Failing to respect this corollary leads to the type I error in hypothesis test, which occurs when a researcher rejects a true null. On the other hand, the alternative hypothesis contains by default the complement statement to the null, and is accepted if and only if there is overwhelming evidence that it is true. Failing to respect this latter corollary leads to the type II error in hypothesis test, which occurs when a researcher fails to reject a false null.

In the above, the first three hypotheses ( $\mathrm{H} 1 \mathrm{to} \mathrm{H} 3)$ together imply that frequent use of digital media by youths positively influence their planetary health interests; while their corresponding alternatives, though not explicitly formulated imply the opposite. The fourth hypothesis addresses the underlying feedback relationship assumed between human health and the environment under the ecological public health view. More specifically, (H4) assumes/states that the ecological public health view is correct (holds), while its implicit alternative suggests otherwise.

\section{Methods}

\subsection{Description of the Data and Variables}

This analysis uses data on the environmental affection and cognition of 187,821 youths respondents from 50 nations worldwide [89], and extracted from the student questionnaire file of the 2015 Program for International Student assessment (PISA) [98]. Administered every 3 years to assess the extent to which students have acquired key competencies for full participation in modern societies, PISA was launched by the Organization for Economic Cooperation and Development (OECD). The OECD report ([99] pp. 65-86), provides a detailed account of its sampling design. The definitions and summary statistics of all used variables are provided in Table A1.

\section{Dependents Variables Description}

Adolescents' level of interests in the biosphere (ecosystem services and sustainability) (IntBiosph), and science-based disease prevention (IntScPrevDis), represent the two dependent variables in our study. Together the two indicators represent adolescent students' interest in "planetary health", which we approach as the health of human civilization and the state of the natural systems on which it depends:

- IntBiosph: defined as $y_{1}$, it is a qualitative ordinal response assuming the values ( 1 - unaware and not interested, 2-Hardly interested, 3-Aware and Interested). As shown in Table A1 its mean value is 2.28 with a standard deviation of 0.79 .

- IntScPrevDis: defined as $y_{2}$, it is also a qualitative ordinal variable that assumes the values (1-unaware and not interested, 2-Hardly interested, 3-Aware and Interested). As shown in Table A1 its mean value is 2.62 with a standard deviation of 0.68 . 


\subsection{Specification of the Econometric Model}

Our Random Utility Model of youth's planetary health interest, presented conceptually in Figure 1 is empirically expressed in the equation system (1), which is a mixed bivariate ordered probit (MBOP) model of youths' interest in the biosphere and in science-based disease prevention. This representation, which from here on we refer to as of the Random Utility-based Mixed Bivariate Ordered Probit (or RUMBOP) model, is an extension of the latent variable framework in [100], which is itself adapted from $[101,102]$. To this end, we let $y_{1}^{*}$ be the latent utility that a youth derive from ecosystem services and sustainability, and $y_{2}^{*}$ be the latent utility that the youth derive from science-based disease prevention (or good health); and state youths' underlying preferences for the biosphere and science-based disease prevention as:

$$
\begin{aligned}
& y_{1 i}^{*}=X^{\prime}{ }_{1 i} \beta_{1}+Z^{\prime}{ }_{1 i} u_{1}+\epsilon_{1 i} \\
& y_{2 i}^{*}=X^{\prime}{ }_{2 i} \beta_{2}+Z^{\prime}{ }_{2 i} u_{2}+\epsilon_{2 i}
\end{aligned}
$$

where $X^{\prime}{ }_{1 i}$, and $X_{2 i}^{\prime}$ denote the fixed effects vectors of regressors, and include the indicators of youths' frequency of digital media consumption (EcoWebVisit, BlogsVisit, BroadScWeb), and the socio-economic and demographic control variables (AGE, Gender, GradeLev, IMMIG, MISCED, FISCED, ESCS); $Z_{1}^{\prime}{ }_{1 i}$, and $Z_{2 i}^{\prime}$ denote the random effects vectors of regressors, and include only (CNTRYID) in the present study. $\beta_{1}$ and $\beta_{2}$ are the corresponding vectors of unknown fixed effects, while $u_{1}$, and $u_{2}$ are the corresponding unknown random country effects. $\epsilon_{1 i}$ and $\epsilon_{2 i}$ denote the random perturbations to the system, and $i$ the individual subscript for each youth respondent. The regular exogeneity assumption $E\left(X^{\prime}{ }_{1 i} \epsilon_{1 i} \mid Z_{1 i}^{\prime}\right)=E\left(X_{2 i}^{\prime} \epsilon_{2 i} \mid Z_{2 i}^{\prime}\right)=0$, of model regressors are maintained.

The observed indicators of adolescent students' levels of interest $y_{1 i}$, and $y_{2 i}$ are linked to their respective latent propensities as:

$$
\begin{gathered}
y_{1 i}= \begin{cases}1-\text { Unaware and Not interested } & \text { if } y_{1 i}^{*} \leq \mu_{1} \\
2-\text { Hardly Interested } & \text { if } \mu_{1} \leq y_{1 i}^{*} \leq \mu_{2} \\
3-\text { Aware and Interested } & \text { if } \mu_{2}<y_{1 i}^{*}\end{cases} \\
y_{2 i}= \begin{cases}1-\text { Unaware and Not interested } & \text { if } y_{2 i}^{*} \leq \delta_{1} \\
2-\text { Hardly Interested } & \text { if } \delta_{1} \leq y_{2 i}^{*} \leq \delta_{2} \\
3-\text { Aware and Interested } & \text { if } \delta_{2}<y_{2 i}^{*}\end{cases}
\end{gathered}
$$

where the cutoffs satisfy $\mu_{1}<\mu_{2}$ and $\delta_{1}<\delta_{2}$, and must be estimated along with the model parameters. To ensure the model is identified, we fix the first threshold values $\mu_{1}=\delta_{1}=0$. Following [103,104], we jointly handle the boundary cases by defining $\mu_{0}=\delta_{0}=-\infty$ and $\mu_{3}=\delta_{3}=+\infty$. In so doing, the joint probability of $y_{1 i}=j$ and $y_{2 i}=k$ is:

$$
\begin{aligned}
\operatorname{Pr}\left(y_{1 i}=j, y_{2 i}=k\right) & =\operatorname{Pr}\left(\mu_{j-1}<y_{1 i}^{*} \leq \mu_{j}, \delta_{k-1}<y_{2 i}^{*} \leq \delta_{k}\right) \\
& =\operatorname{Pr}\left(y_{1 i}^{*} \leq \mu_{j}, y_{2 i}^{*} \leq \delta_{k}\right) \\
& -\operatorname{Pr}\left(y_{1 i}^{*} \leq \mu_{j-1}, y_{2 i}^{*} \leq \delta_{k}\right) \\
& -\operatorname{Pr}\left(y_{1 i}^{*} \leq \mu_{j}, y_{2 i}^{*} \leq \delta_{k-1}\right) \\
& +\operatorname{Pr}\left(y_{1 i}^{*} \leq \mu_{j-1}, y_{2 i}^{*} \leq \delta_{k-1}\right)
\end{aligned}
$$


If $\epsilon_{1 i}$ and $\epsilon_{2 i}$ has joint bivariate Gaussian distribution with correlation $\rho$, then the contribution of each student's to the likelihood function could be formulated as:

$$
\begin{aligned}
\operatorname{Pr}\left(y_{1 i}=j, y_{2 i}=k\right) & =\Phi_{2}\left(\mu_{j}-X^{\prime}{ }_{1 i} \beta_{1}-Z^{\prime}{ }_{1 i} u_{1},\left(\delta_{k}-X^{\prime}{ }_{2 i} \beta_{2}-Z^{\prime}{ }_{2 i} u_{2}\right) \zeta, \tilde{\rho}\right) \\
& -\Phi_{2}\left(\mu_{j-1}-X^{\prime}{ }_{1 i} \beta_{1}-Z^{\prime}{ }_{1 i} u_{1},\left(\delta_{k}-X^{\prime}{ }_{2 i} \beta_{2}-Z^{\prime}{ }_{2 i} u_{2}\right) \zeta, \tilde{\rho}\right) \\
& -\Phi_{2}\left(\mu_{j}-X^{\prime}{ }_{1 i} \beta_{1}-Z^{\prime}{ }_{1 i} u_{1},\left(\delta_{k-1}-X^{\prime}{ }_{2 i} \beta_{2}-Z^{\prime}{ }_{2 i} u_{2}\right) \zeta, \tilde{\rho}\right) \\
& +\Phi_{2}\left(\mu_{j-1}-X^{\prime}{ }_{1 i} \beta_{1}-Z^{\prime}{ }_{1 i} u_{1},\left(\delta_{k-1}-X^{\prime}{ }_{2 i} \beta_{2}-Z{ }_{2 i} u_{2}\right) \zeta, \tilde{\rho}\right)
\end{aligned}
$$

where $\Phi_{2}$ is the standard normal bivariate cumulative distribution function, $\zeta=\frac{1}{\sqrt{1+2 \gamma \rho+\gamma^{2}}}$ and $\tilde{\rho}=\zeta(\gamma+\rho)$. We estimate our above described RUMBOP model, within the R statistical software [105], using the package MCMCglmm [106], which we now describe below.

\subsection{Model Estimation}

Because the RUMBOP model as described in Equations (1)-(5) is just a special case of Generalized Linear Mixed Models (GLMMs) with a probit link function on each of the two outcomes, we adapt the Markov Chain Monte Carlo GLMMs framework by [106] to estimate our model. To achieve this, we stack the latent utilities that adolescent students' derive from the biosphere (ecosystem services, sustainability) $y_{1 i}^{*}$, and science-based disease prevention $y_{2 i}^{*}$, into a single column vector $Y^{*}=\left(y_{1 i}^{*}, y_{2 i}^{*}\right)$ with

$$
Y^{*}=\mathbf{X} \boldsymbol{\beta}+\mathbf{Z u}+\mathbf{e}
$$

where $\mathbf{X}$ and $\mathbf{Z}$ represent respectively the design matrices relating the fixed and random explanatory variables to the latent utilities, with associated parameter vectors $\boldsymbol{\beta} \sim N\left(\boldsymbol{\beta}_{0}, \mathbf{B}\right)$, and $\mathbf{u} \sim N(\mathbf{0}, \mathbf{G})$. $\mathbf{e}$ is the vector of residuals and assumed to be distributed $\mathbf{e} \sim N(\mathbf{0}, \mathbf{R})$.

The joint probability distribution of the location effects $(\boldsymbol{\beta}$ and $\mathbf{u})$ and the residuals $(\mathbf{e})$ is therefore multivariate normal:

$$
\left[\begin{array}{l}
\boldsymbol{\beta} \\
\mathbf{u} \\
\mathbf{e}
\end{array}\right] \sim N\left(\left[\begin{array}{c}
\boldsymbol{\beta}_{0} \\
\mathbf{0} \\
\mathbf{0}
\end{array}\right],\left[\begin{array}{ccc}
\mathbf{B} & \mathbf{0} & \mathbf{0} \\
\mathbf{0} & \mathbf{G} & \mathbf{0} \\
\mathbf{0} & \mathbf{0} & \mathbf{R}
\end{array}\right]\right)
$$

where the expected variance-covariance matrices of the fixed effects, random effects and residuals are respectively $\mathbf{B}, \mathbf{G}$ and $\mathbf{R}$. These are typically unknown, and therefore estimated from the data. The off-diagonal matrices of zeros indicate the prior independence between $\mathbf{B}, \mathbf{G}$ and $\mathbf{R}$.

Typically, parameter estimation for GLMMs involves maximum likelihood (ML) or variants of ML. The solutions are usually iterative and numerically intensive. With recent advances in numerical methods and computing power, Bayesian MCMC methods are now providing more efficient alternatives [107]. For maximum likelihood-based solutions see [108]. Here we rely on the Bayesian approach, following [106]. Since all effects are treated as random in the Bayesian perspective, no distinction is made here between fixed and random effects. As in [109], the design matrices $(\mathbf{W}=[\mathbf{X}, \mathbf{Z}])$ and parameters $\left(\boldsymbol{\theta}=\left[\boldsymbol{\beta}^{\prime}, \mathbf{u}^{\prime}\right]\right)$, are combined to rewrite Equation (6) as:

$$
Y^{*}=\mathbf{W} \boldsymbol{\theta}+\mathbf{e}
$$

Because of the intractability in integrating over the random effects [108], and the multi-dimensionality of the choice probabilities, we rely on Bayesian Markov Chain Monte Carlo (MCMC) methods to identify the $\boldsymbol{\theta}$ parameters. MCMC-based marginalization of the random effects provides a robust alternative strategy for multidimensional integral approximation [110,111].

\subsection{Bayesian MCMC Sampling Schemes for Identification of the Model}

Using the multivariate representation in Equation (8), the normal prior on the location effects $(\boldsymbol{\theta})$ is single blocked Gibbs sampled using the method of [112] explained below. The variance structures 
( $\mathbf{R}$ and $\mathbf{G})$ with normal conjugate priors, are inverse-Wishart distributed, also single blocked Gibbs sampled. The representation of the variance structures ( $\mathbf{R}$ and $\mathbf{G})$ in Equation (7) are given by:

$$
\mathbf{G}=\mathbf{V}_{1} \otimes \mathbf{A}_{1}
$$

where $\mathbf{V}_{1} \otimes \mathbf{A}_{1}$ is the expected variance-covariance matrix corresponding to the random effect (CNTRYID) as initially explained in the formulation of Equation (1). The variance-covariance matrices $(\mathbf{V})$ are low-dimensional and are estimated, while the structured matrices $(\mathbf{A})$ are known high-dimensional matrices. The Kronecker product $(\otimes)$ within component terms allows for between country inter-dependent random effects. Controlling for the between country random variations in student interests, the remaining observed variations are idiosyncratic and accounted for, by the residuals' variance structure $\mathbf{R}$.

\subsubsection{Updating the Latent Utilities from the Biosphere and Science-Based Disease Prevention}

For a given adolescent student in our sample, the conditional density of the 2-dimensional vector $Y_{i}^{*}$ of latent utilities they derive from the biosphere (ecosystem services, sustainability), and science-based disease prevention is:

$$
P\left(Y_{i}^{*} \mid \mathbf{y}, \boldsymbol{\theta}, \mathbf{R}, \mathbf{G}\right) \propto f_{i}\left(y_{i} \mid Y_{i}^{*}\right) f_{N}\left(e_{i} \mid \mathbf{r}_{i} \mathbf{R}_{/ i}^{-1} \mathbf{e}_{/ i}, r_{i}-\mathbf{r}_{i} \mathbf{R}_{/ i}^{-1} \mathbf{r}_{i}^{\prime}\right)
$$

where $f_{N}$ is the multivariate normal density with specified mean vector and variance-covariance matrix. Hence Equation (10) suggests that the conditional density of the latent utility vector for youth respondent $i$, is proportional to the product of the conditional distribution of her revealed interests in the biosphere and science-based disease prevention $y_{i}$, given the latent utilities $Y_{i}^{*}$ and the probability density of the utility residuals. The 2-dimensional latent vector of utility residuals $e_{i}$ for youth respondent $i$ is conditionally distributed normal. The conditioning is on the $2 \times(N-1)$ residuals associated with the other youth respondents, with the notation $/ i$ denoting vectors or matrices with the $i^{\text {th }}$ row and or column removed. This conditional distribution takes into account potential correlations between the random disturbances to the utilities that youths derive from the biosphere and science-based disease prevention (see Figure 1).

$$
P\left(y_{k}^{*} \mid \mathbf{y}, \boldsymbol{\theta}, \mathbf{R}, \mathbf{G}\right) \propto p_{i}\left(y_{i} \mid y_{k}^{*}\right) f_{N}\left(\mathbf{e}_{k} \mid \mathbf{0}, \mathbf{R}_{k}\right)
$$

where $k$ denote an index on the blocks of latent propensities with non-zero residual covariances in Equation (8). Since the error terms are assumed to correlate across the two latent utilities for each youth respondent, and also across youths, $(N) \times(2)$ residual correlations are estimated when $k=1$. As such, the conditional density of each individual latent utility $y_{i j}^{*}$ for all $i=1 \cdots N$ and $j=1 \cdots 2$ is obtained by conditioning each $e_{i j}$ on the remaining $1+(N-1) \times 2$ utility residuals. During the burn-in phase, adaptive methods are used to determine an efficient multivariate proposal density with covariance matrix $v \mathbf{M}$. Using the method of [113], we obtain the scalar $v$ such that the proportion of successful jumps in the Markov Chains is optimal at a rate of 0.23 for the multidimensional vector $y_{k}^{*}$ with $k=1$ [114]. The average posterior variance-covariance matrix $\mathbf{M}$ of the single $2 \times N$-dimensional block vector $y_{k}^{*}$ with $k=1$ is updated during each posterior sampling iteration following [115].

\subsubsection{Location Effects Vector Updating}

The vector of location effects $\left(\boldsymbol{\theta}=\left[\boldsymbol{\beta}^{\prime}, \mathbf{u}^{\prime}\right]\right)$, which characterizes the impact of the explanatory factors (including digital media consumption) on youths' derived utilities from the biosphere and science-based disease prevention, is sampled as a block using the methods by [112], involving the solution through Cholesky factorization of the following sparse linear system:

$$
\tilde{\boldsymbol{\theta}}=\mathbf{C}^{-1} \mathbf{W}^{\prime} \mathbf{R}^{-1}\left(\mathbf{1}-\mathbf{W} \boldsymbol{\theta}_{\star}-\mathbf{e}_{\star}\right)
$$


using the R library Csparse [116], where $\mathbf{C}$ is the sparse matrix (containing primarily zeros) representing the coefficient matrix in the model:

$$
\mathbf{C}=\mathbf{W}^{\prime} \mathbf{R}^{-1} \mathbf{W}+\left[\begin{array}{cc}
\mathbf{B}^{-1} & \mathbf{0} \\
\mathbf{0} & \mathbf{G}^{-1}
\end{array}\right]
$$

$\boldsymbol{\theta}_{\star}=\left[\boldsymbol{\beta}_{\star}^{\prime} \mathbf{u}_{\star}^{\prime}\right]$ and $\mathbf{e}_{\star}$ are drawn randomly from the multivariate normal posterior distributions:

$$
\left[\begin{array}{c}
\boldsymbol{\beta}_{\star} \\
\mathbf{u}_{\star}
\end{array}\right] \sim N\left(\left[\begin{array}{c}
\boldsymbol{\beta}_{0} \\
\mathbf{0}
\end{array}\right],\left[\begin{array}{cc}
\mathbf{B} & \mathbf{0} \\
\mathbf{0} & \mathbf{G}
\end{array}\right]\right)
$$

and

$$
\mathbf{e}_{\star} \sim N\left(\mathbf{W} \boldsymbol{\theta}_{\star}, \mathbf{R}\right)
$$

We obtain $\tilde{\boldsymbol{\theta}}+\boldsymbol{\theta}_{\star}$ (see [106], for more details), as a realization from the required probability distribution $P\left(\boldsymbol{\theta} \mid Y^{*}, \mathbf{W}, \mathbf{R}, \mathbf{G}\right)$.

\subsubsection{Variance-Covariance Structures ( $G$ and $R$ ) Updating}

Following the conditional sampling strategy described in [117], the inverse-Wishart prior distribution provides all required information for estimating the variance-covariance structures $\mathbf{G}$ and R. For the $\mathbf{G}$ structure as represented in Equation (9), the associated matrix sum of squares for the single random effect component assumes the following form:

$$
\mathbf{S}=\phi^{\prime} \mathbf{A}^{-1} \boldsymbol{\phi}
$$

where each row of the random effects matrix $\boldsymbol{\phi}$ indexes the relevant row / column of $\mathbf{A}$, and each column of $\boldsymbol{\phi}$ indexes the relevant row/column in $\mathbf{V}$. Furthermore, $\mathbf{A}$ and $\mathbf{V}$ are defined as in Equation (9), and the parameter variance-covariance matrix sampled from the inverse-Wishart prior:

$$
\mathbf{V} \sim \mathbf{I W}\left(\left(\mathbf{S}_{p}+\mathbf{S}\right)^{-1}, n_{p}+n\right)
$$

With $n$ representing the number of rows in the random effects matrix $\boldsymbol{\phi}$, while $\mathbf{S}_{p}$ and $n_{p}$ represent respectively the sum of squares and degrees of freedom of the inverse-Wishart prior.

\subsubsection{Cutoff Points Updating}

Because of the ordinal nature of our modeled youths' revealed preferences (interests) in the biosphere and science-based disease prevention, the methods developed by [118], are used to allow the indirect utilities youths derive from the biosphere and science-based disease prevention, to be updated simultaneously with the cutoff points described in Equations (2) and (3) using a Metropolis Hastings-with-Gibbs sampling update.

\section{Results}

The results of the analysis are divided into two parts; the first part covers univariate and bivariate descriptive statistics, while the second part covers the econometric findings from the Bayesian Markov Chain Monte Carlo estimation of the RUMBOP model.

\subsection{Descriptive Results}

The descriptive results in Figure A1 and Table A1 (see Appendix A) show that our sampled youth respondents come from 50 countries worldwide. About $52.38 \%$ of them are females, while the remaining $47.62 \%$ are males. Their average age is 15.84 years, with a standard deviation of 0.29 . Based on immigration status, the greatest majority of the youth respondents (83.27\%) are natives 
of their country of reporting, followed by $9.03 \%$ second generation expatriates, and finally $7.70 \%$ first-generation. On the basis of grade level in school, the majority of the sampled youth respondents $(83.30 \%)$ are in 10 th grade, followed by $12.02 \%$ in 9 th grade, $3.65 \%$ in 11 th grade, $0.67 \%$ in 8 th grade, $0.27 \%$ in 7 th grade, and finally $0.08 \%$ in 12 th grade. The mean value of the standard normalized scale of the index of economic, social and cultural status (ESCS - estimated across all OECD countries and partner countries on the basis of the following variables: the International Socio-Economic Index of Occupational Status (ISEI); the highest level of education of the student's parents in years of schooling; the PISA index of family wealth; the PISA index of home educational resources; and the PISA index of possessions related to "classical" culture in the family home. See ([99] pp. 339-340) for more details), shows that the average youth respondent in the sample is 0.13 standard deviation above the mean index value across all PISA 2015 respondents. Moreover, Table A1 also show that both parents of the average youth respondent, have at least a post-secondary non-tertiary education, mother (4.50) and father (4.38), based on the UNESCO international standard classification of education. Furthermore, the average youth respondent is at least a regular visitor of ecological websites (3.41), news blogs (3.27) and websites with broad science content (3.06). Finally, Table A1 shows that on average youth respondents are aware of, and somewhat interested in the biosphere (2.28), and science-based disease prevention (2.62).

To understand the unconditional relationships between youths' frequency of digital media consumption and both their interests in the biosphere (IntBioshp) and that in science-based disease prevention (IntScPrevDis), we perform a series of chi-square tests between each of the three digital media types, and the two ordinal outcome measures. The results of these tests are presented along with the corresponding conditional and unconditional frequency distributions in Tables A2 and A3 respectively for "IntBioshp" and "IntScPrevDis". As shown in Table A2 each of the three measures of digital media consumptions (EcoWebVisit, BlogsVisit, and BroadScWeb) are significantly associated with youths' interest in the biosphere (IntBioshp) since the corresponding p-values for these tests are all less than the $5 \%$ significance level. The conditional relative frequency distribution of youth respondents in Table A2 also suggests that globally, more and more youths are consuming at a higher and higher frequency digital media. This latter observation appears to hold for all three measures of digital media consumption- EcoWebVisit (4.5\%, 8.9\%, 28.5\%, 58.1\%), BlogsVisit ( 6.5\%, 11.8\%, 29.3\%, 52.5\%), and BroadScWeb $(7.6 \%, 15.5 \%, 39.9 \%, 37 \%)$. Similarly, the conditional relative frequency distribution of youth respondents in the last row of Table A2 suggest that globally, more and more youths are showing higher and higher interests in the biosphere $(21.2 \%, 29.6 \%$, and $49.2 \%)$. The chi-square tests results and conditional relative frequency distributions of youth respondents in Table A3 show similar global patterns as above described, for higher and higher youths' interests in science-based disease prevention.

\subsection{Econometric Results}

For our MCMC estimation, of the RUMBOP model, we defined 50,000 iterations of the algorithm with a burn-in period of 15,000 iterations, and a thinning interval of 10 iterations. This has led to an effective random sample of 3500 Markov draws, which were then used to estimate the parameters of the model, along with their $95 \%$ confidence intervals (CI). The presentation of these econometric results is divided into five sub-sections; the first subsection covers the interval and point estimates for the random effects, residuals and cutoff points in the RUMBOP model. The second subsection focuses on describing the effects of digital media consumption on youths' interests in the biosphere (ecosystem services and sustainability). The third subsection describes the effects of digital media consumption on youths' interests in science-based disease prevention. The fourth subsection focuses on describing the impacts of the socio-economic and demographic control variables on youths' interests in the biosphere, while the fifth subsection focuses on describing their impacts on youths' interests in science-based disease prevention. 


\subsubsection{Random Effects, Residuals and Cutoff Points Estimates}

The results of the random country variations in adolescent students interests in the biosphere (IntBiosph) and science-based disease prevention (IntScPrevDis) are summarized in Table A4 Since the $95 \%$ confidence intervals on the estimated posterior mean values 0.41 (with CI [0.20;0.69]), and 0.15 (CI $[0.09 ; 0.23]$ ) are void of zero, we conclude their statistical significance at the $5 \%$ level. These results indicate significant cross-country heterogeneity in youths' planetary health interests. Accounting for these random country level disturbances, all remaining variations in youths' interests in the biosphere and science-based disease prevention are idiosyncratic, and described by the residuals' variance-covariance matrix as summarized in Table A5.

The estimated residuals' variance-covariance matrix in Table A5 shows that globally, the conditional variance of youths' interests in the biosphere (ecosystem and sustainability) is 2.09 (with 95\% CI [1.84; 2.40]), while the conditional variance of their interests in science-based disease prevention is lower at 1.58 (with 95\% CI [1.31; 1.81]). Similarly, Table A5 shows a positive and significant covariance value of 1.52 (with 95\% CI [1.45; 1.62]) between youths' interests in the biosphere (IntBiosph), and their interests in science-based disease prevention (IntScPrevDis). This latter result suggests that the more interested adolescent students are in ecosystem services and sustainability, the more interested they tend to also be in science-based disease prevention. Using the estimated covariance value, along with the two estimated variances, we calculate the corresponding correlation coefficient between "IntBiosph" and "IntScPrevDis" to be $\hat{\rho}=0.8353[1.52 /(\sqrt{2.09} * \sqrt{1.58})]$, which indicates a strong positive linear relationship between the two outcomes variables (or dimensions of youths' planetary health interest). The MCMC estimates for the cutoff points $\mu_{2}$ and $\delta_{2}$ as previously discussed in Equation (3), are summarized in Table A6, and show that $\hat{\mu}_{2}=1.56$ (with $95 \%$ CI [1.50; 1.64]) while $\hat{\delta_{2}}=1.02$ (with $95 \%$ CI $\left.[0.97 ; 1.07]\right)$.

\subsubsection{Digital Media Consumption and Youths Interests in the Biosphere}

The results of the effects of digital media consumption on adolescent students' interests in the biosphere are summarized in the first two columns of Table A6, and suggest that digital media consumption significantly influence youths' interests in the biosphere (ecosystem services and sustainability). However, the effects of all three measures of youths' digital media use frequency (EcoWebVisit, BlogsVisit, BroadScWeb) are respectively negative $(-0.2 ;-0.21$; and -0.34 ), indicating that each level increase in youths' reported frequency of ecological websites visits, news blogs visits, and web-browsing on broad science, reduce respectively by $20 \%$ (with $95 \%$ CI $[-0.22 ;-0.18]$ ), $21 \%$ (with 95\% CI [ $-0.23 ;-0.19]$ ) and 34\% (with 95\% CI [ $-0.36 ;-0.32]$ ) their interests in the biosphere (ecosystem services and sustainability).

\subsubsection{Digital Media Consumption and Youths Interests in Science-Based Disease Prevention}

The results of the effects of digital media consumption on adolescent students' interests in science-based diseases prevention, are summarized in the last two columns of Table A6, and appear to be mixed. In fact, each level increase in youths' reported frequency of ecological website visits increases by $3 \%$ (with $95 \%$ CI $[0.02 ; 0.05]$ ) their interests in science-based disease prevention. In contrast, each level increase in youths' reported frequency of news blogs visits, and web-browsing on broad science, both reduce by $11 \%$ (with $95 \%$ CI $[-0.12 ;-0.09]$ ) and $26 \%$ (with $95 \%$ CI $[-0.28 ;-0.24]$ ) respectively, their interests in science-based disease prevention.

\subsubsection{Control Variables and Youths Interests in the Biosphere, and Science-Based Disease Prevention}

The results of the effects of the control variables on adolescent students' joint interests in the biosphere, and science-based disease prevention are summarized in Table A6. These results show that annual increases in adolescent students' age impact positively their interests in both the biosphere by $20 \%$ (with $95 \% \mathrm{CI}[0.18 ; 0.22]$ ), and science-based disease prevention by $18 \%$ (with $95 \% \mathrm{CI}$ 
[0.16; 0.19]). Similarly, each level increase in adolescent students' grade in school increases their interests in both the biosphere and science-based disease prevention by $13 \%$ (with $95 \%$ CI [0.11; 0.15]). Furthermore, each level increase in youth's paternal education raises youths' interests in both the biosphere, and science-based disease prevention by $1 \%$ (with $95 \%$ CI $[0.001 ; 0.02]$ ). Conversely however, a level increase in youth's maternal education, appears to adversely impact youth's interests in both the biosphere by $3 \%$ (with $95 \%$ CI $[-0.10 ;-0.02]$ ) and science-based disease prevention by $2 \%$ (with $95 \%$ CI $[-0.03 ;-0.01]$ ). The coefficient estimates for the effect of gender suggest that compared to female adolescent students, males have $16 \%$ less interest in the biosphere (with 95\% CI [ -0.19 ; $-0.15]$ ), and $53 \%$ less interest in science-based disease prevention (with 95\% CI [ $-0.59 ;-0.49]$ ).

Now turning to the estimated effects of immigration status, Table A6 shows that compared to youth respondents that are natives of their reporting country, first-generation youth immigrants/expatriates have $6 \%$ less interest in ecosystem services and sustainability (with $95 \%$ CI $[-0.10 ;-0.02]$ ), while having $16 \%$ more interest in science-based disease prevention (with $95 \% \mathrm{CI}$ $[0.11 ; 0.20])$. Conversely however, compared to native students, second generation youth expatriates have respectively $9 \%$ (with 95\% CI [0.05; 0.13]) and 17\% (with 95\% CI [0.13; 0.21$]$ ) more interests in the biosphere, and science-based disease prevention. Finally, a one standard deviation increase in youths' normalized index of socio-economic, social, and cultural status is found to increase their interests in the biosphere by $16 \%$ (with $95 \%$ CI $[0.14 ; 0.17]$ ), and that in science-based disease prevention by $14 \%$ (with $95 \%$ CI $[0.12 ; 0.16]$ ).

\section{Discussion}

The recent outbreak and still ongoing experience of the COVID-19 pandemic [11], has demonstrated the cross-country inter-dependence of health systems, food systems and supply chains globally. In doing so, the pandemic offered humanity the opportunity to shift perceptions to a more holistic view of health [19]; a planetary view in line with the ecological public health framework, which recently emerged due to the growing evidence of the complex relationships between human health and the environment [16] .

With the desire to address the challenges of how best to protect and promote human health in an era of global earth's systems disruptions from human activities, coupled with increased digital media consumption; the present study relied on the concept of "planetary health" to investigate the potential of strategically designed and digitally mediated socio-ecological communications, to enhance society's (through its youths) long-term ability to address appropriately ongoing health and ecological crises. To this end, we first operationalized "youths' planetary health interests" using both "their interests in the biosphere (ecosystem services and sustainability)", and "their interests in science-based disease prevention", allowing us to formulate and test four hypotheses. The first three hypotheses (H1 H2 and H3) together implied that frequent use of digital media by the youths globally, positively influenced their planetary health interests. The fourth hypothesis (H4) however, addressed the underlying feedback relationship assumed between human health and the environment under the ecological public health view. Our analysis contributed to the scientific literature in two ways: (i) methodologically, by introducing a random utility-based bivariate ordered probit (RUMBOP) model, which innovates on the previously used models to study sustainability; and (ii) practically, by providing new insights of practical relevance for evidence-based sustainable policy making, not just at national, or global level, but at the planetary level.

Our findings revealed a statistically significant impact of digital media consumption on adolescents' interests in the biosphere. Indeed, all three measures of digital media consumption (in the form of increased frequency of ecological website visits, news blogs visits, and web-browsing on broad science) significantly influenced youths' interests in ecosystem services and sustainability. However, these effects appeared negative suggesting a reduction rather than an increase in youths' interests in the biosphere. Similarly, our findings highlighted a reduction in youths' interests in science-based disease prevention, from their increased frequency of news blogs visits and web-browsing on broad 
science. Conversely, increased frequency of ecological website visits was found to positively influence youth's interests in science-based disease prevention.

Together, the results seem to indicate that in their current state of use, digital media in the form of ecological websites, news blogs, and broad science web-contents are unsuccessful at galvanizing youths' interests in the biosphere (ecosystem services and sustainability). Even more problematic they contribute to youths' being less interested in the state of the natural systems on which their well-being depends on. Furthermore, at the exception of ecological websites which appear successful at nurturing youths' interests in science-based disease prevention, the remaining two digital media (news blogs, broad science web-content) contribute to youths' being less interested in science-based disease prevention. Overall, our findings seem to indicate that if digital media (in the form of ecological websites, news blogs, and broad science web-content) were to maintain their current (2015) influence on youths' interests in ecosystem services, sustainability and science-based disease prevention, then they would be contributing to reduce youth's planetary health interests globally. The long-term consequences of which, in terms of the set 2030 agenda for sustainable development, would eventually be undesirable for nations.

Our findings corroborate the results in [119], which reports that limited quality, interactivity and readability of 69 adolescent-directed Australian-based websites with health promotion contents, are limiting their effectiveness. Our results also align with the "double-edged-sword" characterization of digital media, when used among youths in a residential treatment setting [120]. However, our findings come as a contrast to [121,122], which report digital media to offer exciting new means for engaging and communicating with adolescents and young adults, for the purposes of providing appropriate intervention and education. Perhaps the digital media under consideration in our present analysis (ecological websites, news blogs, and broad science web-content), are yet to catch up with this potential, by strategically designing and diffusing appropriate socio-ecological communications that adequately target the global youth population [92].

In addition to the above-discussed results, our analysis also showed a statistically significant strong and positive correlation ( 0.835 ) between adolescent students' interest in the biosphere (ecosystem services and sustainability) and their interest in science-based disease prevention. This somewhat strong positive dependence between the two dimensions of youths' planetary health interests further support the dynamic relationship between the well-being of the human civilization, and the state of the natural systems on which its depends [20]. It also confirms the appropriateness of the holistic view of health as embraced in the "ecological public health framework" [5] and "planetary health" view [9].

Overall, consistent with [50], our study shows that digital media has heterogeneous effects on youths' interests, depending on the digital media type under consideration. This is further consistent with the diverging reports in the literature over the effect of digital media on adolescent's well-being $[66,123,124]$. Although the literature has mainly focused on digital media effects on youths' well-being in terms of academic performance [125], physical [126], psychological [127], socio-neurological [128], and mental [129] health outcomes. By focusing here on its effects on youth's planetary health interest, the current analysis can extend this strand of literature in a meaningful fashion. This is because increased youths' planetary health interest should contribute to early commitments to science-based health preservation through disease prevention, and ecological conservation by the younger generation. This latter would be key to achieving a socio-economic development that is sustainable at the planetary level.

Furthermore, recall that male adolescents were found to be less interested in both the biosphere and science-based disease prevention compared to their female counterparts. This latter result suggests the presence of a gender-based gradient in youths' planetary health interest, in favor of the female gender. Although our study is pioneering this latter reported finding within the context of the two dimensions of planetary health, some of its sub-dimensionality do align with the gendered nature of ecosystem services already reported in the ecological economics literature [130]. Indeed, Using a heuristic device of the "ecosystem-wellbeing chain" to empirically investigate how women and men are able to benefit from ecosystem services across eight communities in coastal Kenya and 
Mozambique [131], reported significant gender-based differences across several key aspects such as the division of costs and benefits of ecosystem services, knowledge systems, behavioral expectations, institutions, and access to resources. Our results of the effects of parental education on the two dimensions of youth planetary health interests, further confirm the above-discussed gendered effects. Indeed, while increased paternal education appears to unilaterally be raising adolescents students' interest in both the biosphere (ecosystem services and sustainability) and science-based disease prevention, the reverse seems to be observed for increased maternal education.

As previously mentioned in ([100] p.17), when explaining gender-based differences in parental education's influence on youths' technological awareness and expectations within the North American Free Trade Bloc, it could be that past differences in occupational preferences lifestyle values, and field-specific beliefs between men and women worldwide, translated into women globally taking less interests, and therefore specializing less in Science Technology, Engineering, and Mathematics (STEM) fields than men. Despite recent years reported closures of this gap by females in some markets [132], such greater exposure to science for men globally than women in the past, could have potentially contributed to the observed gender-based knowledge gaps on the biosphere and science-based disease prevention at the parental level. In turn, such gendered knowledge gaps could have led to the observed diverging influences of parental education on adolescents' interests in planetary health in general, and ecosystem services in particular as reported in [131]. Indeed such, conjecture finds theoretical support from "Expectancy-value theory" that suggests psychological processes in children and adolescents take place within lager ecological systems such as biological and socio-cultural, which are also linked among others to gender socialization, social stratification, and behavior genetics [133]. Though parental influence is paramount due to parents direct influence on their children prior conception, during pregnancy and childhood, through educational activities and programs that provide the foundations on which later adolescents' health and ecological interests might reside [132]. As such, a couple of policy recommendations can be formulated as presented next.

\section{Conclusions}

\subsection{Implication}

Most environmental communication studies approach the issue of pro-environmental behavior from a reactive policy standpoint, suggesting behavioral changes in reaction to ongoing environmental crises. Reactive policies however, including those driven by crises, tend to have transitory effects and therefore are typically unsustainable, especially in an ever-evolving human-ecological system. Our current "problematization" [134] departs from the reactive standard by positing that socio-economic development, which address the well-being of humanity, while taking into account the biological sphere that makes human life possible, is best achieved proactively at the grassroots level, i.e., by early conditioning of children and adolescents interests in science-based health preservation, and ecological conservation at the planetary scale, through strategic socio-ecological communications delivered via digital media.

Our results showed that in their current state of use, only ecological websites appear successful at achieving this outcome, perhaps because of the quality of their socio-ecological contents. Therefore improving these contents could contribute to reversing the observed negative impacts of the studied digital media on youths' interests in the health of the planet. To further increase the effectiveness of the proposed actions, a global improvement in youths' understanding of digital media and its usage might also prove to be useful [135]. One way to achieve this could be through programs of Digital Education for Sustainable Development (DESD), which could be formalized in several ways, so that each DESD program reflects the unique environmental, social and economic conditions of its locality. In doing so, DESD programs could encourage youths' behaviors, which in the long run create a more sustainable future in terms of environmental integrity, economic viability, and a just society for present and future generations. 
Open source innovative digital platforms [136] could also ensure the needed global cooperation and coordination of the socio-ecological discourse with high enough elaboration to engage the central route processing [137] of every member of the global community (and especially the youths) [138,139]. This latter recommendation finds theoretical support in the Elaboration Likelihood Model (ELM) [90], which predicts more resilient health and environmental attitudes and action tendencies as each member of society is able to consider the evidence from the openly diffused arguments and counter-arguments of socio-ecological discourses.

\subsection{Limits and Future Research Topic}

Despite the significant methodological contributions and insightful practical findings and suggestions, our current study presents a few limitations that contextualize our reported results. First, there is a very limited representation of youth respondents from the African continent in the data at the moment. Second, by being observational in nature, and relying on a retrospective cross-sectional design our study is also limited in its choice of digital media, which were circumscribed to ecological websites, news blogs, and broad science web-contents. A third limitation lies in our characterization of the two dimensions of youths' planetary health interests, which was achieved through two ordinal scale measurements, one for each dimension. Future investigations might benefit from using other digital media including social media, in an experimental setting to examine prospectively the influence of digital media consumption on youths' planetary health interests. In doing so, prospective investigations might gain further by not only relying on data covering youth respondents from all continents, but also using composite indicators of youths' interests in health preservation and ecological conservation to provide a more robust characterization of youths' planetary health interests.

Author Contributions: Conceptualization, I.N.; methodology, I.N. and A.N.; software, I.N.; validation, M.N.A.a. and A.N.; formal analysis, I.N.; investigation, I.N., M.N.A.a. and A.N.; resources, I.N., M.N.A.a. and A.N.; data curation, I.N.; writing-original draft preparation, I.N.; writing-review and editing, M.N.A.a., A.N.; visualization, I.N.; supervision, A.N. and M.N.A.a.; project administration, I.N., A.N. and M.N.A.a.; All authors have read and agreed to the published version of the manuscript.

Funding: This research received no external funding.

Conflicts of Interest: The authors declare no conflict of interest.

\section{Appendix A}

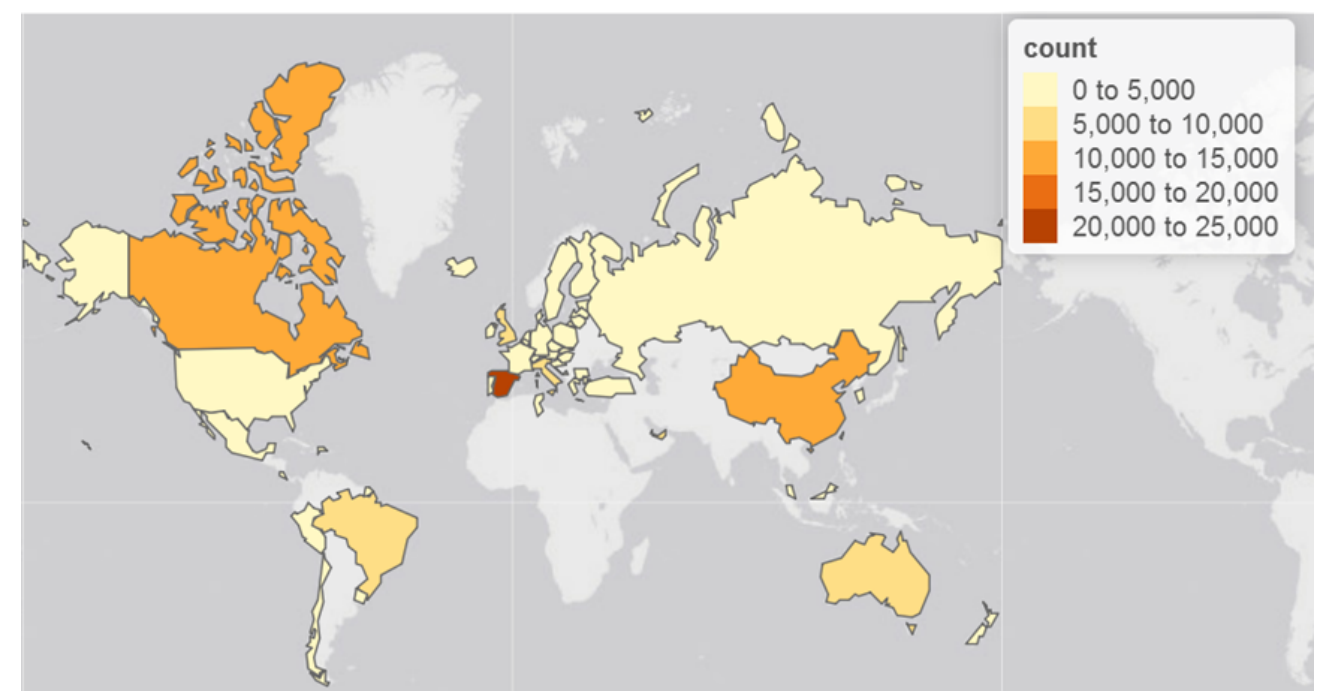

Figure A1. Spatial Distribution of youth respondents count across countries. (Source: The authors own construction; Dynamic web link available at: https:/ /rpubs.com/brassbe1982/PHcount). 
Table A1. Summary Description of the Variables used in the Econometric Modeling. $(\mathrm{N}=187,821)$.

\begin{tabular}{|c|c|c|c|}
\hline Quantitative Variables & (Means and Standard Deviations) & Mean & s.d. \\
\hline \multicolumn{4}{|l|}{ (Dependents) } \\
\hline \multirow[t]{2}{*}{ IntBiosph } & Level of interest in Ecosystem services and Sustainability (Biosphere) & & \\
\hline & $\begin{array}{l}\text { 1: Unaware and Not interested, 2: Hardly Interested, } \\
\text { 3: Aware and Interested; }\end{array}$ & 2.28 & 0.79 \\
\hline \multirow[t]{2}{*}{ IntScPrevDis } & Level of Interest in how science can help prevent disease; & & \\
\hline & $\begin{array}{l}\text { 1: Unaware and Not interested, 2: Hardly Interested, } \\
\text { 3: Aware and Interested; }\end{array}$ & 2.62 & 0.68 \\
\hline \multirow{2}{*}{ (Digital Media Diet) } & How often student do the following: & & \\
\hline & 1-never or Hardly, 2-sometimes, 3-regularly, 4-very often. & & \\
\hline EcoWebVisit & $\hookrightarrow$ Visit Ecological Websites & 3.41 & 0.82 \\
\hline BlogsVisit & $\hookrightarrow$ Follow news via blogs & 3.27 & 0.91 \\
\hline \multicolumn{4}{|l|}{ (Socio-Economic) } \\
\hline AGE & Student's age & 15.84 & 0.29 \\
\hline WEALTH & Student's family wealth index value & 0.14 & 1.34 \\
\hline ESCS & Standardized Index of economic, social and cultural status & 0.13 & 1.14 \\
\hline MISCED & Student's Mother Education level & 4.50 & 1.66 \\
\hline FISCED & Student's Father Education level & 4.38 & 1.65 \\
\hline WFSTUWT & Student final weight in the Data & 161.61 & 240.95 \\
\hline Qualitative Variables & (absolute and percent relative frequencies) & Abs. Freq. & Rel. Freq. \\
\hline \multicolumn{4}{|l|}{ (Demographic) } \\
\hline \multirow[t]{3}{*}{ Gender } & Gender: & & \\
\hline & 1-Female & 9419 & 52.38 \\
\hline & 2-Male & 8562 & 47.62 \\
\hline \multirow[t]{4}{*}{ IMMIG } & Student Immigration status: & & \\
\hline & 1-Native & 14,973 & 83.27 \\
\hline & 2-Second-generation & 1623 & 9.03 \\
\hline & 3-First-generation & 1385 & 7.70 \\
\hline \multirow[t]{7}{*}{ GradeLev } & Student grade level in school: & & \\
\hline & 7th grade & 49 & 0.27 \\
\hline & 8th grade & 121 & 0.67 \\
\hline & 9th grade & 2161 & 12.02 \\
\hline & 10th grade & 14,979 & 83.30 \\
\hline & 11th grade & 657 & 3.65 \\
\hline & 12th grade & 14 & 0.08 \\
\hline CNTRYID & $\begin{array}{l}\text { Unique Identifier for each of the } 50 \text { countries } \\
\text { (used to capture the country-specific effects } \\
\text { with Australia representing the reference country) } \\
\text { (see Figure A1 for its absolute frequency distribution) }\end{array}$ & & \\
\hline
\end{tabular}

Source: Authors' construction using the published data [89].

Table A2. Chi-square test results with conditional and relative frequency distributions in \% for "IntBioshp".

\begin{tabular}{|c|c|c|c|c|c|c|c|c|}
\hline & & \multicolumn{3}{|c|}{ IntBioshp } & \multirow[t]{2}{*}{ Rel. Freq. } & \multicolumn{3}{|c|}{ Chi2 Test } \\
\hline & & 1 & 2 & 3 & & X-sq stat & df & $p$-Value \\
\hline \multirow{4}{*}{ EcoWebVisit } & 1 & 20.3 & 14.7 & 65 & 4.5 & \multirow{4}{*}{$12,355^{* * *}$} & \multirow{4}{*}{6} & \multirow{4}{*}{$<2.2 \times 10^{-16}$} \\
\hline & 2 & 13.2 & 19.7 & 67.1 & 8.9 & & & \\
\hline & 3 & 11.7 & 26.3 & 62 & 28.5 & & & \\
\hline & 4 & 27.2 & 33.9 & 38.9 & 58.1 & & & \\
\hline \multirow{4}{*}{ BlogsVisit } & 1 & 17.2 & 16.4 & 66.4 & 6.5 & \multirow{4}{*}{$12,696^{* * *}$} & \multirow{4}{*}{6} & \multirow{4}{*}{$<2.2 \times 10^{-16}$} \\
\hline & 2 & 11.4 & 21.8 & 66.8 & 11.8 & & & \\
\hline & 3 & 13.1 & 28.2 & 58.7 & 29.3 & & & \\
\hline & 4 & 28.4 & 33.8 & 37.8 & 52.5 & & & \\
\hline \multirow{4}{*}{ BroadScWeb } & 1 & 17 & 19 & 64 & 7.6 & \multirow{4}{*}{$13,049 * * *$} & \multirow{4}{*}{6} & \multirow{4}{*}{$<2.2 \times 10^{-1}$} \\
\hline & 2 & 12.5 & 24.1 & 63.4 & 15.5 & & & \\
\hline & 3 & 15.1 & 30.2 & 54.7 & 39.9 & & & \\
\hline & 4 & 32.2 & 33.5 & 34.3 & 37 & & & \\
\hline Rel. Freq. & & 21.2 & 29.6 & 49.2 & & & & \\
\hline
\end{tabular}

Source: Authors' construction using the published data [89]; *** $p<0.001$. 
Table A3. Chi-square test results with conditional and relative frequency distributions in $\%$ for "IntScPrevDis".

\begin{tabular}{|c|c|c|c|c|c|c|c|c|}
\hline & & \multicolumn{3}{|c|}{ IntScPrevDis } & \multirow[t]{2}{*}{ Rel. Freq. } & \multicolumn{3}{|c|}{ Chi2 Test } \\
\hline & & 1 & 2 & 3 & & X-sq stat & df & $p$-Value \\
\hline \multirow{4}{*}{ EcoWebVisit } & 1 & 16.9 & 9.3 & 73.7 & 4.5 & \multirow{4}{*}{$3097.6^{* * *}$} & \multirow{4}{*}{6} & \multirow{4}{*}{$<2.2 \times 10^{-16}$} \\
\hline & 2 & 10.3 & 11.4 & 78.3 & 8.9 & & & \\
\hline & 3 & 6.9 & 13.2 & 79.9 & 28.5 & & & \\
\hline & 4 & 12.8 & 18.1 & 69.1 & 58.1 & & & \\
\hline \multirow{4}{*}{ BlogsVisit } & 1 & 14.7 & 9.3 & 76.1 & 6.5 & \multirow{4}{*}{$3925.7^{* * *}$} & \multirow{4}{*}{6} & \multirow{4}{*}{$<2.2 \times 10^{-16}$} \\
\hline & 2 & 8 & 11.1 & 80.9 & 11.8 & & & \\
\hline & 3 & 7 & 13.7 & 79.3 & 29.3 & & & \\
\hline & 4 & 13.6 & 18.7 & 67.7 & 52.5 & & & \\
\hline \multirow{4}{*}{ BroadScWeb } & 1 & 13.9 & 10 & 76.1 & 7.6 & \multirow{4}{*}{$5960.5^{* * *}$} & \multirow{4}{*}{6} & \multirow{4}{*}{$<2.2 \times 10^{-16}$} \\
\hline & 2 & 7.9 & 11.2 & 80.9 & 15.5 & & & \\
\hline & 3 & 7.1 & 14.6 & 78.3 & 39.9 & & & \\
\hline & 4 & 16.1 & 20.1 & 63.8 & 37 & & & \\
\hline Rel. Freq. & & 11.1 & 15.7 & 73.2 & & & & \\
\hline
\end{tabular}

Table A4. Posterior estimates with $95 \%$ CI for the random country variations in students Interests.

\begin{tabular}{ccc}
\hline \multirow{2}{*}{ Dependent Variables } & \multicolumn{2}{c}{ CNTRYID } \\
\cline { 2 - 3 } & Posterior Mean & $\mathbf{( 9 5 \% ~ C I ) ~}$ \\
\hline IntBiosph & 0.41 & $(0.20 ; 0.69)$ \\
IntScPrevDis & 0.15 & $(0.09 ; 0.23)$ \\
\hline
\end{tabular}

Note: These correspond to the point and interval estimates of the G-structure.

Table A5. MCMC estimates of the residual variance-covariance matrix for the BOP model of students Interests.

\begin{tabular}{lcl}
\hline & Posterior Mean & $\mathbf{( 9 5 \% ~ C I ) ~}$ \\
\hline Variance of "IntBiosph" & 2.09 & $(1.84 ; 2.40)$ \\
Covariance between "IntBiosph" and "IntScPrevDis" & 1.52 & $(1.45 ; 1.62)$ \\
Variance of "IntScPrevDis" & 1.58 & $(1.31 ; 1.81)$ \\
Correlation Coefficient & $\hat{\rho}=0.8353$ & \\
\hline
\end{tabular}

Note: This corresponds to the point and interval estimates of the R structure.

Table A6. MCMC estimates of the fixed effects along with their 95\% CI for the BOP model of students Interests.

\begin{tabular}{|c|c|c|c|c|}
\hline \multirow{2}{*}{$\begin{array}{l}\text { Units } \\
\text { Fixed Effects }\end{array}$} & \multicolumn{2}{|c|}{ IntBiosph } & \multicolumn{2}{|c|}{ IntScPrevDis } \\
\hline & Posterior Mean & $(95 \% \mathrm{CI})$ & Posterior Mean & $(95 \% \mathrm{CI})$ \\
\hline \multicolumn{5}{|l|}{ Digital Media } \\
\hline EcoWebVisit & -0.2 & $(-0.22 ;-0.18)$ & 0.03 & $(0.02 ; 0.05)$ \\
\hline BlogsVisit & -0.21 & $(-0.23 ;-0.19)$ & -0.11 & $(-0.12 ;-0.09)$ \\
\hline BroadScWeb & -0.34 & $(-0.36 ;-0.32)$ & -0.26 & $(-0.28 ;-0.24)$ \\
\hline \multicolumn{5}{|l|}{ Control Variables } \\
\hline AGE & 0.2 & $(0.18 ; 0.22)$ & 0.18 & $(0.16 ; 0.19)$ \\
\hline Gender_Male & -0.16 & $(-0.19 ;-0.15)$ & -0.53 & $(-0.59 ;-0.49)$ \\
\hline GradeLev & 0.13 & $(0.11 ; 0.15)$ & 0.13 & $(0.11 ; 0.15)$ \\
\hline \multicolumn{5}{|l|}{ IMMIG } \\
\hline First Gen & -0.06 & $(-0.10 ;-0.02)$ & 0.16 & $(0.11 ; 0.20)$ \\
\hline Second Gen & 0.09 & $(0.05 ; 0.13)$ & 0.17 & $(0.13 ; 0.21)$ \\
\hline MISCED & -0.03 & $(-0.03 ;-0.02)$ & -0.02 & $(-0.03 ;-0.01)$ \\
\hline FISCED & 0.01 & $(0.001 ; 0.02)$ & 0.01 & $(0.001 ; 0.02)$ \\
\hline ESCS & 0.16 & $(0.14 ; 0.17)$ & 0.14 & $(0.12 ; 0.16)$ \\
\hline Cutoff points & 1.56 & $(1.50 ; 1.64)$ & 1.02 & $(0.97 ; 1.07)$ \\
\hline \multicolumn{5}{|c|}{ MCMC Algorithm specification } \\
\hline Number of Iterations & \multicolumn{4}{|c|}{50,000} \\
\hline Burn-in period & \multicolumn{4}{|c|}{15,000} \\
\hline Thinning interval & \multicolumn{4}{|c|}{10} \\
\hline Effective Sample Size & \multicolumn{4}{|c|}{3500} \\
\hline
\end{tabular}




\section{References}

1. Myers, S.S. Planetary health: Protecting human health on a rapidly changing planet. Lancet 2017, 390, $2860-2868$. [CrossRef]

2. Demaio, A.R.; Rockström, J. Human and planetary health: Towards a common language. Lancet 2015, 386, e36-e37. [CrossRef]

3. Whitmee, S.; Haines, A.; Beyrer, C.; Boltz, F.; Capon, A.G.; de Souza Dias, B.F.; Ezeh, A.; Frumkin, H.; Gong, P.; Head, P.; et al. Safeguarding human health in the Anthropocene epoch: Report of The Rockefeller Foundation-Lancet Commission on planetary health. Lancet 2015, 386, 1973-2028. [CrossRef]

4. McKinney, A. A Planetary Health Approach to Study Links Between Pollution and Human Health. Curr. Pollut. Rep. 2019, 5, 394-406. [CrossRef]

5. Lang, T.; Rayner, G. Ecological public health: The 21st century's big idea? An essay by Tim Lang and Geof Rayner. BMJ 2012, 345, e5466. [CrossRef]

6. Horton, R.; Beaglehole, R.; Bonita, R.; Raeburn, J.; McKee, M.; Wall, S. From public to planetary health: A manifesto. Lancet 2014, 383, 847. [CrossRef]

7. Lerner, H.; Berg, C. A comparison of three holistic approaches to health: One health, EcoHealth, and planetary health. Front. Vet. Sci. 2017, 4, 163. [CrossRef]

8. Prior, J.; Cusack, C.M.; Capon, A. The role of pliability and transversality within trans/disciplinarity: Opening university research and learning to planetary health. In Transdisciplinary Theory, Practice and Education; Springer: Berlin, Germany, 2018; pp. 57-71.

9. Parsons, J. Global and Planetary Health. In Good Health and Well-Being; Springer: Cham, Switzerland, 2020; pp. 225-236.

10. Frumkin, H. Sustaining Life: Human Health-Planetary Health Linkages. In Health of People, Health of Planet and Our Responsibility; Springer: Cham, Switzerland, 2020; pp. 21-37.

11. Sohrabi, C.; Alsafi, Z.; O’Neill, N.; Khan, M.; Kerwan, A.; Al-Jabir, A.; Iosifidis, C.; Agha, R. World Health Organization declares global emergency: A review of the 2019 novel coronavirus (COVID-19). Int. J. Surg. 2020, 76, 71-76. [CrossRef]

12. Bénassy-Quéré, A.; Marimon, R.; Pisani-Ferry, J.; Reichlin, L.; Schoenmaker, D.; Weder, B. 13 COVID-19: Europe needs a catastrophe relief plan. In Mitigating the COVID Economic Crisis: Act Fast and Do Whatever It Takes; CEPR Press: London, UK, 2020; Volume 121.

13. Maffioli, E.M. How Is the World Responding to the Novel Coronavirus Disease (COVID-19) Compared with the 2014 West African Ebola Epidemic? The Importance of China as a Player in the Global Economy. Am. J. Trop. Med. Hyg. 2020, 102, 924-925. [CrossRef]

14. Baldwin, R.; Tomiura, E. Thinking ahead about the trade impact of COVID-19. In Economics in the Time of COVID-19; CEPR Press: London, UK, 2020; Volume 59.

15. McKibbin, W.J.; Fernando, R. The Global Macroeconomic Impacts of COVID-19: Seven Scenarios. CAMA Working Paper No. 19/2020. Available online: http:/ /dx.doi.org/10.2139/ssrn.3547729 (accessed on 27 March 2020).

16. Brown, A.; Horton, R. A planetary health perspective on COVID-19: A call for papers. Lancet 2020, 395, 1099. [CrossRef]

17. Lim, S.S.; Allen, K.; Bhutta, Z.A.; Dandona, L.; Forouzanfar, M.H.; Fullman, N.; Gething, P.W.; Goldberg, E.M.; Hay, S.I.; Holmberg, M.; et al. Measuring the health-related Sustainable Development Goals in 188 countries: A baseline analysis from the Global Burden of Disease Study 2015. Lancet 2016, 388, 1813-1850. [CrossRef]

18. Nakatani, H. Global strategies for the prevention and control of infectious diseases and non-communicable diseases. J. Epidemiol. 2016, 26, 171-178. [CrossRef] [PubMed]

19. Heymann, D.L.; Shindo, N. COVID-19: What is next for public health? Lancet 2020, 395, 542-545. [CrossRef]

20. Pérez-Escamilla, R. Food security and the 2015-2030 sustainable development goals: From human to planetary health: Perspectives and opinions. Curr. Dev. Nutr. 2017, 1, e000513. [CrossRef] [PubMed]

21. De Leeuw, A.; Valois, P.; Ajzen, I.; Schmidt, P. Using the theory of planned behavior to identify key beliefs underlying pro-environmental behavior in high-school students: Implications for educational interventions. J. Environ. Psychol. 2015, 42, 128-138. [CrossRef]

22. Clark, H.; Coll-Seck, A.M.; Banerjee, A.; Peterson, S.; Dalglish, S.L.; Ameratunga, S.; Balabanova, D.; Bhan, M.K.; Bhutta, Z.A.; Borrazzo, J.; et al. A future for the world's children? A WHO-UNICEF-Lancet Commission. Lancet 2020, 395, 605-658. [CrossRef] 
23. Wang, G.; Zhang, Y.; Zhao, J.; Zhang, J.; Jiang, F. Mitigate the effects of home confinement on children during the COVID-19 outbreak. Lancet 2020, 395, 945-947. [CrossRef]

24. Farley, J. Ecosystem services: The economics debate. Ecosyst. Serv. 2012, 1, 40-49. [CrossRef]

25. Yun, J.J.; Won, D.; Park, K. Entrepreneurial cyclical dynamics of open innovation. J. Evol. Econ. 2018, 28, 1151-1174. [CrossRef]

26. Yun, J.J.; Zhao, X.; Park, K.; Shi, L. Sustainability Condition of Open Innovation: Dynamic Growth of Alibaba from SME to Large Enterprise. Sustainability 2020, 12, 4379. [CrossRef]

27. Rodríguez-Labajos, B.; Martínez-Alier, J. The economics of ecosystems and biodiversity: Recent instances for debate. Conserv. Soc. 2013, 11, 326-342. [CrossRef]

28. Wahl, D.C. Design for human and planetary health: A transdisciplinary approach to sustainability. Manag. Nat. Resour. Sustain. Dev. Ecol. Hazards 2006, 99, 285.

29. Doshi, R.; Diwekar, U.; Benavides, P.T.; Yenkie, K.M.; Cabezas, H. Maximizing sustainability of ecosystem model through socio-economic policies derived from multivariable optimal control theory. Clean Technol. Environ. Policy 2015, 17, 1573-1583. [CrossRef]

30. Menshutkin, V.; Rukhovets, L.; Filatov, N. Ecosystem modeling of freshwater lakes (review): 2. Models of freshwater lake's ecosystem. Water Resour. 2014, 41, 32-45. [CrossRef]

31. Yun, J.J.; Liu, Z. Micro-and Macro-Dynamics of Open Innovation with a Quadruple-Helix Model. Sustainability 2019, 11, 3301. [CrossRef]

32. Cabezas, H.; Fath, B.D. Towards a theory of sustainable systems. Fluid Phase Equilibria 2002, 194, 3-14. [CrossRef]

33. Shastri, Y.; Diwekar, U. Sustainable ecosystem management using optimal control theory: Part 1 (deterministic systems). J. Theor. Biol. 2006, 241, 506-521. [CrossRef]

34. Manski, C.F. The structure of random utility models. Theory Decis. 1977, 8, 229. [CrossRef]

35. Brown, B.W.; Walker, M.B. The random utility hypothesis and inference in demand systems. Econom. J. Econom. Soc. 1989, 57, 815-829. [CrossRef]

36. Walker, J.; Ben-Akiva, M. Generalized random utility model. Math. Soc. Sci. 2002, 43, 303-343. [CrossRef]

37. Batley, R. On ordinal utility, cardinal utility and random utility. Theory Decis. 2008, 64, 37-63. [CrossRef]

38. Marschak, J. Binary-choice constraints and random utility indicators (1960). In Economic Information, Decision, and Prediction; Springer: Berlin, Germany, 1974; pp. 218-239.

39. Becker, G.M.; DeGroot, M.H.; Marschak, J. Stochastic models of choice behavior. Behav. Sci. 1963, 8, 41-55. [CrossRef]

40. Fechner, G.T. Elements of Psychophysics; Breitkopf and Hartel: Leipzip, Germany, 2012.

41. Thurstone, L.L. A law of comparative judgment. Psychol. Rev. 1994, 101, 266. [CrossRef]

42. Luce, R.D. Individual Choice Behavior: A Theoretical Analysis; Courier Corporation: Chelmsford, MA, USA, 2012.

43. McFadden, D. The revealed preferences of a government bureaucracy: Theory. Bell J. Econ. 1975, 6, 401-416. [CrossRef]

44. Kleinert, S.; Horton, R. Adolescent health and wellbeing: A key to a sustainable future. Lancet 2016, 387, $2355-2356$. [CrossRef]

45. Mokdad, A.H.; Forouzanfar, M.H.; Daoud, F.; Mokdad, A.A.; El Bcheraoui, C.; Moradi-Lakeh, M.; Kyu, H.H.; Barber, R.M.; Wagner, J.; Cercy, K.; et al. Global burden of diseases, injuries, and risk factors for young people's health during 1990-2013: A systematic analysis for the Global Burden of Disease Study 2013. Lancet 2016, 387, 2383-2401. [CrossRef]

46. Ki-moon, B. Sustainability-Engaging future generations now. Lancet 2016, 387, 2356-2358. [CrossRef]

47. Bennett, E.M.; Peterson, G.D.; Gordon, L.J. Understanding relationships among multiple ecosystem services. Ecol. Lett. 2009, 12, 1394-1404. [CrossRef]

48. Liang, Y.; Kee, K.F.; Henderson, L.K. Towards an integrated model of strategic environmental communication: advancing theories of reactance and planned behavior in a water conservation context. J. Appl. Commun. Res. 2018, 46, 135-154. [CrossRef]

49. Wartella, E.; Rideout, V.; Montague, H.; Beaudoin-Ryan, L.; Lauricella, A. Teens, health and technology: A national survey. Media Commun. 2016, 4, 13-23. [CrossRef]

50. Chassiakos, Y.L.R.; Radesky, J.; Christakis, D.; Moreno, M.A.; Cross, C. Children and adolescents and digital media. Pediatrics 2016, 138, e20162593. [CrossRef] [PubMed] 
51. Twenge, J.M.; Martin, G.N.; Spitzberg, B.H. Trends in US Adolescents' media use, 1976-2016: The rise of digital media, the decline of TV, and the (near) demise of print. Psychol. Pop. Media Cult. 2019, 8, 329. [CrossRef]

52. Bailey, J.; Mann, S.; Wayal, S.; Hunter, R.; Free, C.; Abraham, C.; Murray, E. Sexual health promotion for young people delivered via digital media: A scoping review. Public Health Res. 2015, 3, 1-119. [CrossRef] [PubMed]

53. Benjamin, K.; Potts, H.W. Digital transformation in government: Lessons for digital health? Digit. Health 2018, 4, 1-5. [CrossRef] [PubMed]

54. Carreiro, S.; Chai, P.R.; Carey, J.; Lai, J.; Smelson, D.; Boyer, E.W. mHealth for the detection and intervention in adolescent and young adult substance use disorder. Curr. Addict. Rep. 2018, 5, 110-119. [CrossRef]

55. Lauvsnes, A.D.F.; Langaas, M.; Toussaint, P.; Gråwe, R.W. Mobile Sensing in Substance Use Research: A Scoping Review. Telemed. e-Health 2020. [CrossRef]

56. Nebeker, C. mHealth Research Applied to Regulated and Unregulated Behavioral Health Sciences. J. Law Med. Ethics 2020, 48, 49-59. [CrossRef]

57. Patterson, S.P.; Hilton, S.; Flowers, P.; McDaid, L.M. What are the barriers and challenges faced by adolescents when searching for sexual health information on the internet? Implications for policy and practice from a qualitative study. Sex. Transm. Infect. 2019, 95, 462-467. [CrossRef]

58. Bago, J.L.; Lompo, M.L. Exploring the linkage between exposure to mass media and HIV awareness among adolescents in Uganda. Sex. Reprod. Healthc. 2019, 21, 1-8. [CrossRef]

59. Fleary, S.A.; Joseph, P.; Pappagianopoulos, J.E. Adolescent health literacy and health behaviors: A systematic review. J. Adolesc. 2018, 62, 116-127. [CrossRef]

60. Guo, S.; Yu, X.; Davis, E.; Armstrong, R.; Riggs, E.; Naccarella, L. Adolescent Health Literacy in Beijing and Melbourne: A Cross-Cultural Comparison. Int. J. Environ. Res. Public Health 2020, 17, 1242. [CrossRef] [PubMed]

61. Gandhi, S.; Chen, S.; Hong, L.; Sun, K.; Gong, E.; Li, C.; Yan, L.L.; Schwalm, J.D. Effect of mobile health interventions on the secondary prevention of cardiovascular disease: Systematic review and meta-analysis. Can. J. Cardiol. 2017, 33, 219-231. [CrossRef] [PubMed]

62. Kassebaum, N.; Kyu, H.H.; Zoeckler, L.; Olsen, H.E.; Thomas, K.; Pinho, C.; Bhutta, Z.A.; Dandona, L.; Ferrari, A.; Ghiwot, T.T.; et al. Child and adolescent health from 1990 to 2015: Findings from the global burden of diseases, injuries, and risk factors 2015 study. JAMA Pediatr. 2017, 171, 573-592. [PubMed]

63. Azzopardi, P.S.; Hearps, S.J.; Francis, K.L.; Kennedy, E.C.; Mokdad, A.H.; Kassebaum, N.J.; Lim, S.; Irvine, C.M.; Vos, T.; Brown, A.D.; et al. Progress in adolescent health and wellbeing: Tracking 12 headline indicators for 195 countries and territories, 1990-2016. Lancet 2019, 393, 1101-1118. [CrossRef]

64. Crompton, H.; Burke, D.; Gregory, K.H. The use of mobile learning in PK-12 education: A systematic review. Comput. Educ. 2017, 110, 51-63. [CrossRef]

65. Newland, L.A.; Mourlam, D.; Strouse, G. A phenomenological exploration of the role of digital technology and media in children's subjective well-being. Child Indic. Res. 2018, 11, 1563-1583. [CrossRef]

66. Orben, A.; Przybylski, A.K. The association between adolescent well-being and digital technology use. Nat. Hum. Behav. 2019, 3, 173-182. [CrossRef]

67. Vannucci, A.; Ohannessian, C.M. Social media use subgroups differentially predict psychosocial well-being during early adolescence. J. Youth Adolesc. 2019, 48, 1469-1493. [CrossRef]

68. Cangas, A.J.; Fínez, M.J.; Morán, C.; Navarro, N.; Moldes, P. Mental Health, New Technologies, and Wellbeing for Adolescents. In Enhancing Resilience in Youth; Springer: Berlin, Germany, 2019; pp. 233-243.

69. Goodall, D.; Ban, S.; Birks, E.; Clifton, A. New perspectives on the contribution of digital technology and social media use to improve the mental wellbeing of children and young people: A state-of-the-art review. Neonatal Paediatr. Child Health Nurs. 2013, 16, 19.

70. James, C.; Davis, K.; Charmaraman, L.; Konrath, S.; Slovak, P.; Weinstein, E.; Yarosh, L. Digital life and youth well-being, social connectedness, empathy, and narcissism. Pediatrics 2017, 140, S71-S75. [CrossRef]

71. Loebach, J.; Tilleczek, K.; Chaisson, B.; Sharp, B. Keyboard warriors? Visualising technology and well-being with, for and by indigenous youth through digital stories. Vis. Stud. 2019, 34, 281-297. [CrossRef]

72. Loid, K.; Täht, K.; Rozgonjuk, D. Do pop-up notifications regarding smartphone use decrease screen time, phone checking behavior, and self-reported problematic smartphone use? Evidence from a two-month experimental study. Comput. Hum. Behav. 2020, 102, 22-30. [CrossRef] 
73. Dhir, A.; Yossatorn, Y.; Kaur, P.; Chen, S. Online social media fatigue and psychological wellbeing-A study of compulsive use, fear of missing out, fatigue, anxiety and depression. Int. J. Inf. Manag. 2018, 40, 141-152. [CrossRef]

74. Elhai, J.D.; Rozgonjuk, D.; Alghraibeh, A.M.; Yang, H. Disrupted daily activities from interruptive smartphone notifications: Relations with depression and anxiety severity and the mediating role of boredom proneness. Soc. Sci. Comput. Rev. 2019. [CrossRef]

75. Marino, C.; Gini, G.; Vieno, A.; Spada, M.M. The associations between problematic Facebook use, psychological distress and well-being among adolescents and young adults: A systematic review and meta-analysis. J. Affect. Disord. 2018, 226, 274-281. [CrossRef]

76. Sha, P.; Sariyska, R.; Riedl, R.; Lachmann, B.; Montag, C. Linking internet communication and smartphone use disorder by taking a closer look at the Facebook and WhatsApp applications. Addict. Behav. Rep. 2019, 9, 100148. [CrossRef]

77. Sindermann, C.; Elhai, J.D.; Montag, C. Predicting tendencies towards the disordered use of facebook's social media platforms: On the role of personality, impulsivity, and social anxiety. Psychiatry Res. 2020, 285, 112793. [CrossRef]

78. Xin, M.; Xing, J.; Pengfei, W.; Houru, L.; Mengcheng, W.; Hong, Z. Online activities, prevalence of Internet addiction and risk factors related to family and school among adolescents in China. Addict. Behav. Rep. 2018, 7, 14-18. [CrossRef]

79. Domoff, S.E.; Borgen, A.L.; Foley, R.P.; Maffett, A. Excessive use of mobile devices and children's physical health. Hum. Behav. Emerg. Technol. 2019, 1, 169-175. [CrossRef]

80. Rodgers, R.F.; Slater, A.; Gordon, C.S.; McLean, S.A.; Jarman, H.K.; Paxton, S.J. A biopsychosocial model of social media use and body image concerns, disordered eating, and muscle-building behaviors among adolescent girls and boys. J. Youth Adolesc. 2020, 49, 399-409. [CrossRef]

81. Bachi, L.; Ribeiro, S.C.; Hermes, J.; Saadi, A. Cultural Ecosystem Services (CES) in landscapes with a tourist vocation: Mapping and modeling the physical landscape components that bring benefits to people in a mountain tourist destination in southeastern Brazil. Tour. Manag. 2020, 77, 104017. [CrossRef]

82. Figueroa-Alfaro, R.W.; Tang, Z. Evaluating the aesthetic value of cultural ecosystem services by mapping geo-tagged photographs from social media data on Panoramio and Flickr. J. Environ. Plan. Manag. 2017, 60, 266-281. [CrossRef]

83. Karasov, O.; Vieira, A.A.B.; Külvik, M.; Chervanyov, I. Landscape coherence revisited: GIS-based mapping in relation to scenic values and preferences estimated with geolocated social media data. Ecol. Indic. 2020, 111, 105973. [CrossRef]

84. Baumeister, C.F.; Gerstenberg, T.; Plieninger, T.; Schraml, U. Exploring cultural ecosystem service hotspots: Linking multiple urban forest features with public participation mapping data. Urban For. Urban Green. 2020, 48, 126561. [CrossRef]

85. Workman, J.E.; Lee, S.H.; Jung, K. Trendsetting, Cultural Awareness, Cultural Receptivity, and Future Orientation among the Young Generation of Chinese College Students: Trendsetters Critically Matter. Sustainability 2019, 11, 5853. [CrossRef]

86. Ayres, C. Political Participation, Digital Media and Communication for Development and Social Change: The Perpective of the Youth Citizens. In Proceedings of the 52nd International Scientific Conference on Economic and Social Development, Porto, Portugal, 17-18 April 2020; p. 53.

87. Babu, A.; Kurian, A.S.; Ammu Priya, P.; Cherian, E.S.; Babu, S. U-REPORT: Helping Hand In Defendless Situation. Int. J. Inf. 2019, 8, 13-17.

88. Gatera, G.; Pavarini, G. The voices of children in the global health debate. Lancet 2020, 395, 541-542. [CrossRef]

89. Niankara, I. Cross-national Data Sample on the Environmental Affection and Cognition of Adolescent Students of Varying Interests in Ecosystem Services and Sustainability. Data Brief 2019, 22, 312-318. [CrossRef]

90. Petty, R.E.; Briñol, P.; Teeny, J.; Horcajo, J. The Elaboration Likelihood Model: Changing attitudes toward exercising and beyond. In Persuasion and Communication in Sport, Exercise, and Physical Activity; Routledge: Abingdon, UK, 2017; pp. 22-37. 
91. Chang, H.; Zhang, L.; Xie, G.X. Message framing in green advertising: The effect of construal level and consumer environmental concern. Int. J. Advert. 2015, 34, 158-176. [CrossRef]

92. Pope, J.P.; Pelletier, L.; Guertin, C. Starting off on the best foot: A review of message framing and message tailoring, and recommendations for the comprehensive messaging strategy for sustained behavior change. Health Commun. 2018, 33, 1068-1077. [CrossRef]

93. Gifford, R.D.; Chen, A.K. Why aren't we taking action? Psychological barriers to climate-positive food choices. Clim. Chang. 2017, 140, 165-178. [CrossRef]

94. Chernov, G.; McCombs, M. Philosophical orientations and theoretical frameworks in media effects: Agenda setting, priming and their comparison with framing. Agenda Setting J. 2019, 3, 63-81. [CrossRef]

95. Domínguez, P.R.; Gámiz, F.; Gil, M.; Moreno, H.; Zamora, R.M.; Gallo, M.; de Brugada, I. Providing choice increases children's vegetable intake. Food Qual. Prefer. 2013, 30, 108-113. [CrossRef]

96. Newell, B.R.; McDonald, R.I.; Brewer, M.; Hayes, B.K. The psychology of environmental decisions. Annu. Rev. Environ. Resour. 2014, 39, 443-467. [CrossRef]

97. Gonzalez, A.M.; Reynolds-Tylus, T.; Quick, B.L. Clustering energy and water conservation behaviors as choices: Examining the moderating roles of message elaboration and involvement. Appl. Environ. Educ. Commun. 2020, 1-16. [CrossRef]

98. OECD. Programme for International Student Assessment (PISA) 2015 Database: Stduent Questionnaire Data file; Organization for Economic Co-operation and Development: Paris, France, 2016.

99. OECD. PISA 2015 Technical Report: Chapter 04-Sample Design; Organization for Economic Co-operation and Development: Paris, France, 2017.

100. Niankara, I.; Adkins, L.C. Youth Awareness and Expectations about GMOs and Nuclear Power Technologies within the North American Free Trade Bloc: A Retrospective Cross-Country Comparative Analysis. J. Open Innov. Technol. Mark. Complex. 2020, 6, 34. [CrossRef]

101. Niankara, I.; Zoungrana, D.T. Interest in the biosphere and students environmental awareness and optimism: A global perspective. Glob. Ecol. Conserv. 2018, 16, e00489. [CrossRef]

102. Sajaia, Z. Maximum likelihood estimation of a bivariate ordered probit model: implementation and Monte Carlo simulations. Stata J. 2008, 4, 1-18.

103. Jackman, S. Models for Ordered Outcomes [PDF Document]. 2000. Available online: http://www.stanford. edu/class/polisci203/ordered.pdf (accessed on 25 March 2018).

104. McKelvey, R.D.; Zavoina, W. A statistical model for the analysis of ordinal level dependent variables. J. Math. Sociol. 1975, 4, 103-120. [CrossRef]

105. R Core Team. R: A Language and Environment for Statistical Computing; R Foundation for Statistical Computing: Vienna, Austria, 2015.

106. Hadfield, J.D. MCMC Methods for Multi-response Generalized Linear Mixed Models: The MCMCglmm R package. J. Stat. Softw. 2010, 33, 1-22. [CrossRef]

107. Rastogi, M.K.; Merovci, F. Bayesian estimation for parameters and reliability characteristic of the Weibull Rayleigh distribution. J. King Saud Univ.-Sci. 2018, 30, 472-478. [CrossRef]

108. McCulloch, C.E.; Searle, S.R. Generalized Linear, and Mixed Models; Wiley: New York, NY, USA, 2001.

109. Niankara, I. Evaluating health consumers' preferences stability through joint estimation of revealed and stated health insurance preferences data. Int. J. Econ. Bus. Res. 2018, 15, 236-256. [CrossRef]

110. Zhao, Y.; Staudenmayer, J.; Coull, B.A.; Wand, M.P. General Design Bayesian Generalized Linear Mixed Models. Stat. Sci. 2006, 21, 35-51. [CrossRef]

111. Brown, W.; Draper, D. A comparison of bayesian and likelihood-based methods for fitting multilevel methods. Bayesian Anal. 2006, 1, 473-514. [CrossRef]

112. Gracia-Cortes, L.A.; Sorensen, D. Alternative Implementations of Monte Carlo EM Algorithms for Likelihood Inferences. Genet. Sel. Evol. 2001, 33, 443-452. [CrossRef] [PubMed]

113. Ovaskainen, O.; Rekola, H.; Meyke, E.; Arjas, E. Bayesian Methods for Analyzing Movements in heterogeneous landscapes from mark-recapture data. Ecology 2008, 89, 542-554. [CrossRef] [PubMed]

114. Gelman, A.; Carlin, J.B.; Stern, H.H.; Rubin, D.B. Bayesian Data Analysis, 2nd ed.; Chapman \& Hall: London, UK, 2004. 
115. Haario, H.; Saksman, E.; Tamminen, J. An Adaptive Metropolis Algorithm. Bernoulli 2001, 7, $223-242$. [CrossRef]

116. Davis, A.T. Direct Methods for Sparse Linear Systems; Fundamentals of Algoritms; SIAM: Philadelphia, PA, USA, 2006.

117. Korsgaard, I.R.; Andersen, A.H.; Soresen, D. A Useful Reparametrisation to obtain Samples from Conditional inverse Wishart Distributions. Genet. Sel. Evol. 1999, 31, 177-181. [CrossRef]

118. Cowles, M.K. Accelerating Monte Carlo Markov chain convergence for cumulative-link generalized linear models. Stat. Comput. 1996, 6, 101-111. [CrossRef]

119. Ruan, S.; Raeside, R.; Singleton, A.; Redfern, J.; Partridge, S.R. Limited engaging and interactive online health information for adolescents: A systematic review of Australian websites. Health Commun. 2020, 1-10. [CrossRef]

120. Good, B.; Mishna, F. “Double-edged sword” of Digital Media Use among Youth in Residential Treatment: Perspectives of Service Providers. Resid. Treat. Child. Youth 2019, 1-25. [CrossRef]

121. Yonker, L.M.; Zan, S.; Scirica, C.V.; Jethwani, K.; Kinane, T.B. “Friending" teens: Systematic review of social media in adolescent and young adult health care. J. Med. Internet Res. 2015, 17, e4. [CrossRef] [PubMed]

122. Harris, S.K.; Aalsma, M.C.; Weitzman, E.R.; Garcia-Huidobro, D.; Wong, C.; Hadland, S.E.; Santelli, J.; Park, M.J.; Ozer, E.M. Research on clinical preventive services for adolescents and young adults: Where are we and where do we need to go? J. Adolesc. Health 2017, 60, 249-260. [CrossRef] [PubMed]

123. Fitzpatrick, C.; Burkhalter, R.; Asbridge, M. Adolescent media use and its association to wellbeing in a Canadian national sample. Prev. Med. Rep. 2019, 14, 100867. [CrossRef] [PubMed]

124. Stiglic, N.; Viner, R.M. Effects of screentime on the health and well-being of children and adolescents: A systematic review of reviews. BMJ Open 2019, 9, e023191. [CrossRef]

125. Marker, C.; Gnambs, T.; Appel, M. Active on Facebook and Failing at School? Meta-Analytic Findings on the Relationship Between Online Social Networking Activities and Academic Achievement. Educ. Psychol. Rev. 2018, 30, 651-677. [CrossRef]

126. Tripathi, G.; Ahad, M.A. Effects of Social Media on Social, Mental, and Physical Health Traits of Youngsters. In Computational Intelligence in Data Mining; Springer: Berlin, Germany, 2019; pp. 685-695.

127. Przybylski, A.K.; Weinstein, N. Digital Screen Time Limits and Young Children's Psychological Well-Being: Evidence From a Population-Based Study. Child Dev. 2019, 90, e56-e65. [CrossRef]

128. Twenge, J.M.; Campbell, W.K. Associations between screen time and lower psychological well-being among children and adolescents: Evidence from a population-based study. Prev. Med. Rep. 2018, 12, 271-283. [CrossRef]

129. Nereim, C.D.; Bickham, D.S.; Rich, M.O. 234. Social Media and Adolescent Mental Health: Who You are and What You do Matter. J. Adolesc. Health 2020, 66, S118-S119. [CrossRef]

130. Perkins, P.E. Feminist ecological economics and sustainability. J. Bioecon. 2007, 9, 227-244. [CrossRef]

131. Fortnam, M.; Brown, K.; Chaigneau, T.; Crona, B.; Daw, T.M.; Gonçalves, D.; Hicks, C.; Revmatas, M.; Sandbrook, C.; Schulte-Herbruggen, B. The gendered nature of ecosystem services. Ecol. Econ. 2019, 159, 312-325. [CrossRef]

132. Wang, M.T.; Degol, J.L. Gender gap in science, technology, engineering, and mathematics (STEM): Current knowledge, implications for practice, policy, and future directions. Educ. Psychol. Rev. 2017, 29, 119-140. [CrossRef] [PubMed]

133. Eccles, J. Female achievement patterns: Attributions, expectancies, values, and choice. J. Soc. Issues 1983, 1, 1-22.

134. Weder, F.; Voci, D.; Vogl, N.C. Environmental Discourses and Natural Resource Related Claims in German, Austrian, Slovenian and Italian Media. J. Sustain. Dev. 2019, 12 , 39-54. [CrossRef]

135. Zosh, J.M.; Lytle, S.R.; Golinkoff, R.M.; Hirsh-Pasek, K. Putting the education back in educational apps: How content and context interact to promote learning. In Media Exposure during Infancy and Early Childhood; Springer: Berlin, Germany, 2017; pp. 259-282.

136. Hossain, M.; Islam, K.Z. Ideation through online open innovation platform: Dell IdeaStorm. J. Knowl. Econ. 2015, 6, 611-624. [CrossRef]

137. Petty, R.E.; Cacioppo, J.T. Communication and Persuasion: Central and Peripheral Routes to Attitude Change; Springer: Berlin, Germany, 2012. 
138. Chesbrough, H. The future of open innovation: The future of open innovation is more extensive, more collaborative, and more engaged with a wider variety of participants. Res. Technol. Manag. 2017, 60, 35-38. [CrossRef]

139. West, J.; Salter, A.; Vanhaverbeke, W.; Chesbrough, H. Open Innovation: The Next Decade. Res. Policy 2014, 43, 805-811. [CrossRef]

(C) 2020 by the authors. Licensee MDPI, Basel, Switzerland. This article is an open access article distributed under the terms and conditions of the Creative Commons Attribution (CC BY) license (http:/ / creativecommons.org/licenses/by/4.0/). 